\title{
The Role of Risk Climate and Ethical Self-interest Climate in Predicting Unethical Pro-organisational Behaviour
}

\author{
Elizabeth Sheedy ${ }^{1}\left[\right.$ D Patrick Garcia ${ }^{2} \cdot$ Denise Jepsen $^{2}$
}

Received: 15 July 2019 / Accepted: 18 May 2020 / Published online: 23 May 2020

(c) The Author(s) 2020

\begin{abstract}
Unethical pro-organisational behaviour (UPB) is an ongoing concern, prompting the need for more nuanced understanding of the workplace environment most likely to inhibit it. This study considers the role of risk climate, sometimes referred to as risk culture, as well as ethical climate, for reducing UPB. The study investigates whether four risk climate factors (avoidance, valued, proactive and manager) can, by focusing on the long-term consequences of UPB to the organisation, and providing guidance on behavioural norms, reduce UPB misconduct. Surveying employees in three financial institutions we found that only one of the risk climate factors, avoidance, is consistently associated with UPB. On the other hand, a self-interested, (un)ethical climate significantly increases UPB in all samples. In multi-climate analysis, we found that risk climate factors interacted with ethical climate to predict UPB. That is, when employees perceive that the workplace ethos is not self-interested, three factors of risk climate-avoidance, proactive and manager-significantly predict UPB. UPB is least likely when self-interest is low, avoidance risk climate is low, proactive risk climate is high and manager risk climate is high. Implications for leaders are discussed.
\end{abstract}

Keywords Ethical climate $\cdot$ Financial services $\cdot$ Risk climate $\cdot$ Risk culture $\cdot$ Misconduct $\cdot$ Multiple climates $\cdot$ Unethical pro-organisational behaviour

\section{Introduction}

Employee conduct in financial institutions is an ongoing matter for scrutiny. In the UK for example, the Payment Protection Insurance scandal (The Guardian 2016) meant thousands of customers were sold a product for which they had no need. At Wells Fargo in the US, employees opened some two million accounts without proper customer authorization, resulting in customers being charged unwarranted fees (Tayan 2016). In Australia following years of scandal, a government-established public inquiry, the 'Royal Commission into Misconduct in the Banking, Superannuation and Financial Services Industry', detailed a plethora of misconduct toward customers in consumer lending, financial

Elizabeth Sheedy

elizabeth.sheedy@mq.edu.au

1 Department of Applied Finance, Macquarie Business School, Macquarie University, Room 739, 4 Eastern Road, Sydney, NSW 2109, Australia

2 Department of Management, Macquarie Business School, Macquarie University, Sydney, Australia advice, superannuation (pension) funds and insurance (Royal Commission 2018). Notoriously, institutions charged service fees to customers whom they knew to be dead and clearly incapable of benefitting from any further service ( $\mathrm{p}$. 122). These examples illustrate a specific type of unethical behaviour known as unethical pro-organisational behaviour, or UPB. Such behaviour violates societal norms but brings benefit to the organisation, at least in the short term, and hence indirect benefit to the employee through monetary incentives and promotion prospects (Umphress and Bingham 2011).

Traditionally researchers have investigated ethical climate as a potential solution to UPB and other forms of workplace misconduct. The purpose of this paper is to consider the possible role of risk climate, along with ethical climate, for reducing UPB.

Ethical climate, defined as perceptions of what constitutes right behaviour (Martin and Cullen 2006), was first proposed by Victor and Cullen $(1987,1988)$ to explain the variation in ethical decision-making between workplaces. Their ground-breaking two-dimensional model proposes nine ethical climate types. Egoistic ethical climates are among 
the least preferred for producing ethical outcomes (Martin and Cullen 2006; Simha and Cullen 2012). In such environments, employees perceive that the organisation implicitly condones self-interested behaviour, even to the detriment of others (Victor and Cullen 1988). Self-focused moral reasoning prevails, with little regard for the interests of external stakeholders such as customers. Employees are therefore more likely to behave in a manner that exploits customers or other external stakeholders for the good of the organisation and ultimately themselves. Applying this approach, leaders might reduce UPB by promoting a less self-interested approach to work (Umphress and Bingham 2011).

The Victor and Cullen $(1987,1988)$ approach considers shared perceptions by members of the organisation regarding the appropriate philosophical lens for assessing ethical dilemmas. On one dimension the focus is on stakeholder priority, that is, external versus internal focus, while the other dimension is concerned with choosing appropriate benchmarks for virtuous behaviour, such as laws and professional codes or personal morality. While some of these philosophical lenses have proven useful for predicting behaviours of ethical interest, the various ethical climates of Victor and Cullen have little to say about behavioural norms. Exactly what behaviour is expected of employees in the face of ethical dilemmas? This is a potential weakness as recent scholarship in the area of organisational climate has emphasised 'the shared meaning organisational members attach to the events, policies, practices, and procedures they experience and the behaviours they see being rewarded, supported, and expected' (Ehrhart et al. 2013, p. 286).

Given the ongoing prevalence of UPB and the potential weakness highlighted above, it is important to further explore other workplace conditions that can successfully temper it. In their review and critique of the organisational climate literature, Kuenzi and Schminke (2009) argue that since multiple climates exist in organisations, interactions between these climates are an important area for future research. To date, most investigations of organisational climate have considered single climates in isolation, but this approach is 'unlikely to be the most productive path to creating a full and accurate understanding of how work climates affect individual and collective outcomes within organisations' (p. 705). This view is endorsed by Schneider et al. (2013) in their recommendations for future research in the field of organisational climate and culture (p. 369). For example, Myer et al. (2016) investigate interactions between service and ethical climates. The study finds a complementary relationship between the two climates for enhancing business profitability, highlighting the benefits of multiclimate analysis.

The purpose of this paper is therefore to consider risk climate, an organisational climate with potential to complement ethical climate, in relation to UPB. Risk climate refers to shared staff perceptions of the risk management practices and behaviours that are expected, valued and supported (Sheedy et al. 2017). A favourable risk climate, sometimes referred to in the industry as a risk culture, may potentially reduce UPB by focusing on the long-term adverse consequences of UPB for the organisation including fines, legal costs, reputational damage and increased regulation. Unlike the ethical climates, risk climate is not just a criterion for identifying which practices are acceptable, it also guides employees in how to behave in relation to suspect practices. For example, in workplaces with a favourable risk climate, employees would be quick to identify and report practices with the potential for adverse consequences. Rather than sweeping these issues under the carpet, managers would be responsive, ensuring that business practices are promptly rectified. Managers would model appropriate behaviour, and be more likely to reward and encourage exemplary employees.

We therefore investigate the efficacy of the four-factor risk climate framework due to Sheedy, Griffin and Barbour (2017) for addressing UPB. To create the potential for nuanced understanding and allow possible complementarity of workplace climates, we follow recommendations of Kuenzi and Schminke (2009) and Schneider et al. (2013) to investigate a multiple-climate model of UPB, also including an ethical climate construct in the tradition of Victor and Cullen (1987, 1988). We use ethical self-interest (ESI) climate (Arnaud and Schminke 2012) which guides employees in relation to stakeholder priority, directing attention either to internal stakeholders on the one hand or alternatively to the interests of external parties such as customers. Risk climate provides employees with complementary cues in relation to the behavioural norms for acting on those concerns, and also directing attention to the consideration of the long-term consequences of business practices. We investigate how, separately and together, ESI and risk climates influence UPB misconduct. We empirically investigate the links between four dimensions of risk climate and UPB, the association between ESI climate and UPB, and the interaction between the risk climate dimensions and ESI climate on UPB. Our proposed theoretical model is summarised in Fig. 1.

The contribution of the paper is to confirm the fundamental importance of ethical workplace climates for addressing unethical behaviour, while also showing the value of risk climate as a complementary workplace focus. As such, the paper contributes to the nascent multi-climate literature. This is achieved using employee surveys in three financial services firms that vary in the extent to which they exhibit risk and ethical climate and also their 'for-profit' versus 'not-for-profit' status. The fact that our results are confirmed across all three organisations, despite their heterogeneous characteristics, speaks to the generalisability of the findings. 
Fig. 1 The proposed theoretical model

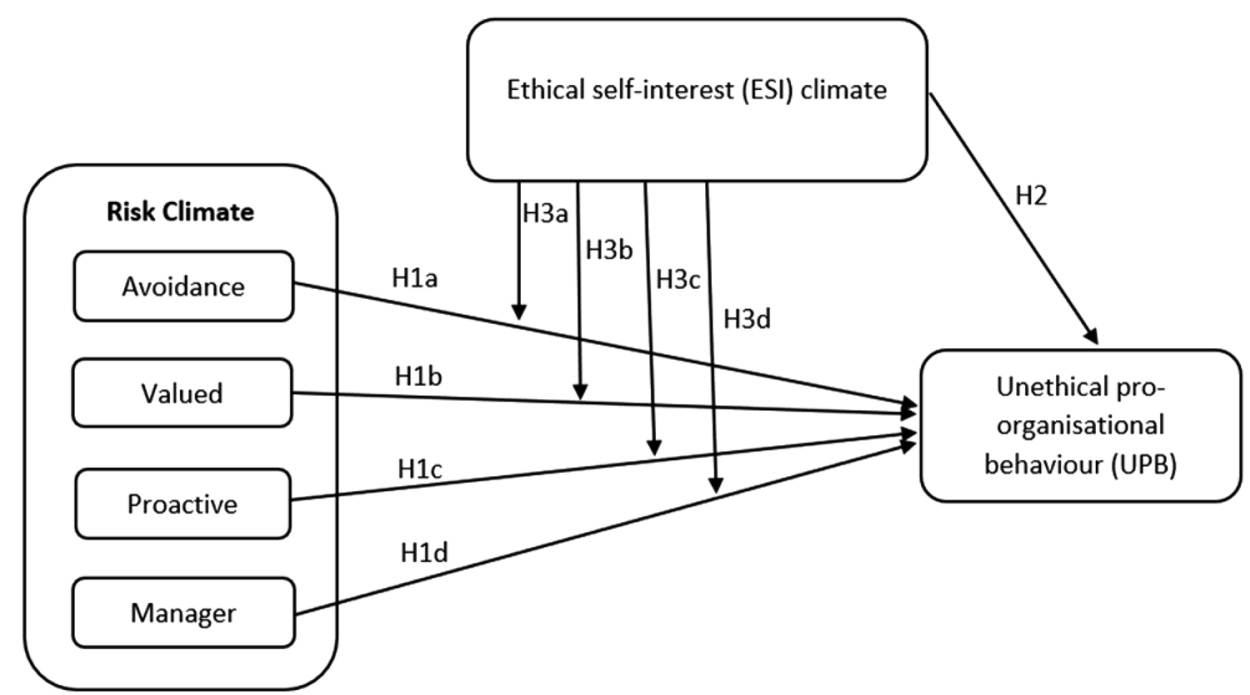

We first present what is known about UPB, then introduce risk climate, before discussing the possible moderating role of ethical climate on UPB. Results of a survey study in three financial services firms are followed by discussion of how these results might be applicable more widely in other organisations exposed to possible UPB.

\section{Theoretical Development and Hypotheses}

\section{Unethical Pro-organisational Behaviour (UPB)}

While some unethical workplace behaviours-such as funds embezzlement, theft of company property and absenteeism-are intended to benefit the employee and harm the organisation, in contrast, employee UPB is intended to benefit the individual indirectly by assisting the organisation. These self-interested actions are motivated by anticipation of future reward from the organisation which could take the form of bonuses, promotion or higher status. UPB is considered a form of unethical behaviour as it violates societal values regardless of whether it is consistent with or defies organisational expectations (Umphress and Bingham 2011). Some examples of UPB include manipulating accounts to overstate financial results, withholding dangerous product information from customers or regulators, putting fake ratings on restaurant or hotel review sites and selling to vulnerable customers who neither understand nor need the products. Note that in all these examples there is benefit to the organisation at the expense of external stakeholders.

Several individual factors have been shown to be positively related to self-interested UPB behaviour. Employees with strong organisational identification are more likely to engage in UPB than employees with weak organisational identification. Strong perceptions of belonging to the organisation cause employees to serve the organisation, even to the detriment of external stakeholders (Chen et al. 2016; Umphress et al. 2010). This relationship is moderated and strengthened by the individual's positive reciprocity beliefs (Umphress et al. 2010). That is, the employee anticipates personal reward flowing from actions that benefit the organisation. This latter finding highlights the importance of selfinterest in motivating UPB. In other words, employees who engage in UPB are motivated by a combination of service to the organisation and self-interest.

UPB can be distinguished from other behaviours such as workplace deviance and pro-social rule breaking (PSRB). The difference between UPB and workplace deviance lies in the motivation behind the behaviour. That is, workplace deviance is perpetrated with the intention to harm the wellbeing of the organisation, its members, or both (Robinson and Bennett 1995), whereas UPB is committed with the intention to promote the effective functioning of the organisation, its members, or both (Umphress and Bingham 2011). Indeed, the factors that promote workplace deviance also differ from that of UPB. For instance, workplace deviance has been found to be influenced by perceived injustice or mistreatment (Garcia et al. 2015), whereas UPB is motivated by perceptions of belonging and strong identification with the organisation (Umphress et al. 2010). Examples of workplace deviance include repeating gossip about a coworker or about the organisation, making sexist or racist jokes in the workplace and taking work property home without permission.

In the case of PSRB, employees intentionally deviate from established workplace policies in order to help the organisation (Morrison 2006). Morrison identifies three possible motivations for PSRB, being efficiency, concern for co-workers or concern for customers. While PSRB and UPB are both committed to benefit the organisation, 
they differ in terms of what is being violated. PSRB violates explicit organisationally defined policies pertaining to how members of the organisation are supposed to execute their jobs (Morrison 2006). On the contrary, UPB involves the violation of hypernorms or social and moral standards (Umphress and Bingham 2011). As such, UPB involves the violation of more absolute and global standards of ethical behaviour as opposed to more specific rules mandated by the organisation.

UPB is likely to be relevant in multiple industries and across national cultures. In the US for example, UPB has been studied in cross-industry samples (Umphress et al. 2010; Effelsberg et al. 2014; Castille et al. 2018) and restaurant workers (Matherne and Litchfield 2012). In China, UPB has been studied in public sector workers (Miao et al. 2013), retail employees (Chen et al. 2016) and textiles workers (Lee et al. 2017).

Theoretically, organisational factors also are likely to be positively related to UPB. Amoral workplaces are environments in which organisational norms fail to encourage ethical behaviour, perhaps through the influence of amoral leadership and performance goals (Umphress and Bingham 2011). In amoral workplaces, behaviour contrary to societal notions of ethicality is tolerated and even expected, even if not formally required. Employees in amoral environments will be likely to morally disengage, resulting in UPB (Umphress and Bingham 2011).

There are few empirical investigations of the link between workplace climate and UPB other than Castille, Buckner and Thoroughgood (2018). This study shows that while Machiavellians are more willing than non-Machiavellians to engage in UPB, bottom line mentality climate perceptions do not explain the relationship. We note, however, that ethical climate has been linked to specific behaviours that could be interpreted as UPB. Peterson (2002) for example, supports an association between a self-interested climate and exaggerating the benefits of a product or service, while Wimbush, Shepard and Markham (1997) link instrumental ethical climate to behaviour designed to deceive a government client. In neither study is the unethical behaviour specifically identified as UPB.

\section{Risk Climate}

Risk climate is defined as 'shared perceptions among employees of the relative priority given to risk management, including perceptions of the risk-related practices and behaviours that are expected, valued and supported' (Sheedy et al. 2017). Risk climate is potentially relevant to UPB since UPB produces the risk of various adverse longterm consequences including fines, legal costs, reputational damage and increased regulation. While devoid of moral concern for external stakeholders, risk climate is relevant to
UPB as it considers the potential impact of this behaviour on the organisation.

Risk climate should be seen in the context of the broader discipline of risk management which became prominent in the late twentieth century (Power 2004). Power argues that the focus on risk management in organisations developed in the context of an increasingly litigious and regulated society. Organisations of all types and in all industries found the need to defend themselves against reputational damage, legal costs and regulatory fines. Nocco and Stulz (2006) are early users of the term 'enterprise risk management', where all risks are viewed together in a strategic framework, creating a long-term competitive advantage that translates into shareholder value. Mikes (2009) documents the variation in risk management practices early in the twentieth century.

Notably, international risk management standards were promulgated in 2009 (ISO31000, 2009). These standards, updated in 2018, claim relevance to all organisations in all sectors. According to these standards, the purpose of risk management is the creation and protection of value. The standards claim that the effectiveness of risk management will depend on integration into governance and all the activities of the organisation.

Interest in organisational risk management was heightened by the financial crisis that began in 2007, which many view, at its core, as a failure of risk management and governance (Senior Supervisor's Group 2009). Too often directors were ignorant of the risks taken by the organisation, and oversight was lacking. From this followed governance reforms related to risk management (e.g. Financial Stability Board 2013), which have been widely adopted beyond the financial services sector (OECD 2014).

Risk governance, where the board takes responsibility for the organisation's risk management, is typically accomplished through a range of mechanisms including a board risk committee, an independent risk/compliance function, internal audit and high-status risk professionals such as a Chief Risk Officer who may sit on the executive committee (OECD 2014; Financial Stability Board 2013). In the risk governance paradigm, decisions about risk appetite and risk policy are taken at board level, with executives responsible for implementation. A risk management framework includes all the systems and policies used in an organisation for identification, measurement, treatment and reporting of risk.

While risk governance structures and frameworks were initially a post-crisis focus, it became apparent to practitioners that structures and frameworks alone were inadequate. Their effectiveness could be undermined by an organisational climate that prioritised short-term profits rather than long-term resilience. For example, managers at the local level might implicitly condone non-compliance with risk policy in order to achieve short-term performance goals. Similarly, lack of managerial response to risk issues raised 
by employees could lead those employees to conclude that reporting issues is a waste of time. Regular workplace discussion of the importance of short-term profits, little mention of risk priorities and low status for risk management professionals may create a workplace environment inconsistent with formally espoused policies.

This attention on organisational climate led to increasing calls for assessment, description and definition of a 'risk culture' in financial institutions (e.g. Institute for International Finance 2008). It is important to note that the term 'risk culture' is used exclusively in the practitioner literature but the popular usage of the term, focusing on behavioural norms rather than underlying values (Financial Stability Board 2014), is more aligned with climate constructs (Schneider et al. 2013).

A need was identified at that time for an organisational climate that prioritised risk management behaviour, where risk policies would be fully implemented even if they compromised short-term profits, and where risk management would be widely seen as important for the long-term sustainability of the organisation. Employees and managers throughout the organisation would take seriously their role in risk management, going above and beyond mere compliance. The international standards relating to risk management (International Organization for Standardisation 2018) highlight the need for aligning risk management with the strategy, objectives and 'culture' of the organisation.

Consistent with the literature on focused organisational climates (Schneider et al. 2013), Sheedy et al. (2017) provide a framework and measure for risk climate in financial institutions. Here risk climate is defined as 'the shared perceptions among employees of the relative priority given to risk management, including perceptions of the risk-related practices and behaviours that are expected, valued and supported' (p. 103). A favourable risk climate is expected to predict risk management behaviour such as compliance with risk policy, speaking up about risk issues and personal accountability for risk management going beyond mere compliance. While developed using financial institution samples, the four-factor model is potentially applicable in the wide range of industries that have adopted enterprise risk management principles. Evidence to support the hypothesised relationship between risk climate and behaviour is provided in Sheedy and Griffin (2018) and Sheedy et al. (2019).

In considering the relevance of risk climate to UPB, it is important to note that UPB produces short-term profits but creates risks for longer-term outcomes. If discovered, UPB can result in remediation programs for customers who have been wronged, legal costs, regulatory fines, increased regulation that damages future business prospects and loss of revenues due to reputational risks. The more effectively the organisation is regulated, the greater the chance of discovery and subsequent sanctions, and the more potent risk climate is likely to be for addressing UPB. Risk climate addresses the issue of UPB indirectly, via the impact of UPB on the organisation itself.

A favourable risk climate, combined with effective risk policies and frameworks, ought to ensure that losses from UPB are managed to acceptable levels from the perspective of the organisation. In financial institutions, where shareholder primacy has historically prevailed (Marin 2012), customer and other stakeholder outcomes have not usually been seen as an end in themselves. This highlights the important difference between risk climate and ESI climate, with its focus on the interests of external stakeholders for their own sake. Risk climate as practised in financial institutions is devoid of any ethical dimension. That is, the organisation is concerned about customer and other stakeholder outcomes only to the extent they produce consequential losses for the organisation via higher costs such as fines, legal costs, customer remediation programs and reputational damage. A workplace climate with a strong focus on risk management is likely to be most effective in reducing UPB if the consequences of UPB are significant and the probability of discovery is high.

We consider all four dimensions of risk climate identified by Sheedy et al. (2017) as possible predictors of UPB due to their clear theoretical relevance for reducing UPB. The first factor, 'avoidance', is the perception that risk issues and policy breaches are ignored, downplayed or excused. While organisations often have policies designed to prevent UPB, the policy breaches of top performers in sales/profits are sometimes excused. This signals to other staff that such policies are of secondary importance and that short-term sales/ profits are the true priority. UPB is likely to flourish in such an environment since the policies designed to prevent misconduct are seen as unimportant. Similarly, if staff questions about the long-term consequences of business practices are ignored or swept under the carpet, staff are likely to form the opinion that senior leaders will not allow anything to stand in the way of short-term profits. This signals to employees that risk management policies promoting the reporting of issues are mere whitewashing. Believing that reporting issues is unproductive, employees may then fail to report their concerns, making remedial action even less likely.

'Valued' refers to the perception that risk management is genuinely valued within the organisation and not merely espoused. This could be demonstrated by the fact that specialist risk managers have authority and respect within the organisation. Further, staff recognise that risk management helps the organisation achieve its goals rather than blocking the achievement of its goals. When staff perceive risk management as genuinely valued and supported by the organisation they are more likely to engage in risk management behaviours and comply with policies designed to ensure the 
firm meets its long-term objectives. This would inhibit UPB with its adverse long-term consequences.

The 'proactive' dimension of risk climate is the perception that risk issues and events are proactively identified and addressed. Practices that are valued and encouraged in a proactive risk climate include identifying potential and emerging risks, analysing risk events to improve business practices, regular discussion and consideration of risk in all key decision-making, and rapid escalation of risk incidents, issues and concerns. In such a climate, UPB is likely to be reduced as employees will identify the possibility of fines and reputational damage resulting from UPB. Poor business practices likely to lead to adverse long-term consequences will therefore come under scrutiny early, before problems emerge on a large scale. When misconduct occurs, it will be escalated to senior leaders. Lessons will be learned and business practices will be reformed.

Finally, 'manager' relates to perceptions that the immediate manager is a strong role model and advocate for risk management. In a positive manager risk climate, managers are likely to remind employees of the priority of risk management, even when the firm is struggling to achieve other objectives such as short-term profits. The manager will model behaviours such as reporting risk events, compliance with risk policy and respect for risk management practices and risk specialists. Where managers highlight through words and actions that the organisation is concerned about long-term outcomes and not just the short-term, employees will be less likely to engage in UPB with its expected adverse longer-term consequences.

We expect all four dimensions of risk climate will impact UPB as follows:

Hypothesis 1a: Avoidance risk climate is positively associated with UPB

Hypothesis 1b: Valued risk climate is negatively associated with UPB

Hypothesis 1c: Proactive risk climate is negatively associated with UPB

Hypothesis 1d: Manager risk climate is negatively associated with UPB.

\section{Ethical Climate}

Ethical climate, defined as perceptions of what constitutes right behaviour (Martin and Cullen 2006), was first proposed by Victor and Cullen $(1987,1988)$. This model proposes nine ethical climate types on two dimensions: ethical theory and locus of analysis. Each of the nine represents a philosophical approach, shared by members of an organisation, for considering ethical dilemmas. Ethical self-interest (ESI) climate, the focus of this study and one of the nine, falls within the broader 'egoistic' or 'instrumental' category.

Egoistic ethical climates are among the least preferred for producing ethical outcomes (Martin and Cullen 2006; Simha and Cullen 2012). In such an environment, employees perceive that the organisation implicitly condones selfinterested behaviour, even to the detriment of others (Victor and Cullen 1988). Informal statements and actions of managers and respected peers create the impression that it is not important to consider external stakeholders, even though there may be formal statements to the contrary. Employees have tacit permission to make decisions focused on their own interests, without regard for consequences beyond the organisation. In a meta-analytic study, Kish-Gephart et al. (2010) find a weak but positive relationship between egoistic ethical climate and unethical choices in the workplace.

Schminke et al. (2005) provide a detailed discussion of some psychometric issues related to the original Ethical Climate Questionnaire (Victor and Cullen 1988) and its use by multiple researchers since the late 1980s. Specifically, not all of the items in the original 26-item scale have loaded consistently on their anticipated factors. Arnaud and Schminke (2012) therefore focused only on the 16 items that have loaded consistently on the expected factors. From these, their study identified two five-item ethical climate factors, namely ESI climate and an 'other-focused' factor. ESI climate corresponds to the pre-conventional level of moral reasoning in Kohlberg's (1984) framework, which supports the exploitation of others for personal gain. Arnaud and Schminke (2012) found that ESI climates were positively related to unethical behaviour in the workplace, consistent with the previously mentioned studies.

As noted above, UPB is fundamentally motivated by selfinterest. Employees with positive reciprocity beliefs engage in UPB so they can benefit the organisation and ultimately themselves through rewards, promotion or status. For example, employees might be willing to lie to customers about the benefits of a product or service in the expectation that higher sales will bring short-term profits for the organisation, which will be rewarded with a cash bonus. We hypothesise, therefore, that a workplace environment that prioritises personal interest is likely to facilitate UPB. In a high ESI climate, employees will be permitted, tacitly or explicitly, to pursue strategies that exploit external stakeholders for the benefit of the firm and ultimately themselves. This prediction is consistent with research by Peterson (2002) and Wimbush, Shepard and Markham (1997) who link instrumental ethical climate to behaviours that could be interpreted as UPB. We expect ESI climate to impact UPB: 
Hypothesis 2: ESI climate is positively associated with UPB.

\section{Interaction Between Risk Climate and ESI Climate}

One of the first to pursue the challenge of a multiple-climate framework was Dov (2008), who proposes that the effect of safety climate will depend on its complimentary climate, work-ownership climate. The same paper posits that interactions between safety climate and ethical climate are worthy of investigation, to better understand the relative importance of pragmatic versus ethical motivations for protecting the safety of employees. Other multi-climate studies have considered the interactive effects of service climate and ethical climate (Jiang et al. 2016; Myer et al. 2016).

Stewart et al. (2011) examine the interactive effect of diversity and ethical climate perceptions on turnover intentions. The researchers argue that the two climates will enhance one another, such that the combination is more effective that either climate in isolation. In a sample of US warehouse employees, they find that ethical climate moderates the relationship between diversity climate and turnover intentions, such that turnover intentions were lowest among workers perceiving both a pro-diversity and highly ethical climate.

In a similar way, we predict that a favourable risk climate will complement low ESI climate in reducing UPB. Low ESI climate guides employees with regard to stakeholder priority, indicating the need to consider external stakeholders such as customers. The interests of outsiders are an end in themselves, not merely a means to the end of organisational interests. A critique of the ESI climate construct, however, is its failure to provide explicit guidance on behavioural norms to address ethical challenges, such as proactive discussion of work practices.

Risk climate, by contrast, has no intrinsic concern with the interests of outsiders, directing employees rather to consider the longer-term consequences to the organisation of business practices. Risk climate would link concerns about customer outcomes to potential adverse organisational outcomes such as fines and reputational damage. A further strength of this construct is the focus on the how employees ought to behave in relation to troubling business practices such as speaking up, discussing in a productive manner and resolving issues. The combination of favourable risk climate with low ESI climate should mean that employees will a) consider the interests of external stakeholders, b) consider the longer-term organisational consequences of harm to these stakeholders and c) understand how to respond appropriately when they have concerns.

Where there is a high ESI climate, risk climate may be less effective in curbing UPB. If employees fail to consider the potential for customers, for example, to be harmed by their behaviour, then they would be less likely to see the potential for legal costs, fines and reputational damage resulting from the harm to customers. Lack of cognisance of one is likely to necessarily lead to a lack of cognisance of the other. Employees focusing on organisational interests alone may be more likely to ignore the risk of harm to external stakeholders, especially if they assess the risk of consequential organisational damage to be low.

Turning to the factors of risk climate, we suggest that low rates of ESI climate combine with low rates of avoidance to produce low levels of UPB. In such an environment, employees will recognise that customer outcomes are important, and perceive that the organisation is unlikely to tolerate or ignore poor customer outcomes with their propensity to harm the organisation itself. When ESI climate is high, the issue of avoidance is less relevant since employees focused on their own self-interest may not even recognise the possibility that business practices are harmful to customers.

Similarly, a favourable risk climate on the dimension of valued will give employees confidence that the risks associated with UPB will be taken seriously. Where risk management is embraced by staff as a way of helping the organisation to achieve its goals, employees will be more likely to be engaged in the risk management process. This mechanism will be complemented by low ESI which helps staff to consider how business practices might impinge on customer outcomes.

As indicated earlier, the proactive dimension of risk climate emphasises practices such as identifying potential and emerging risks, analysing risk events to improve business practices, regular discussion and consideration of risk in all key decision-making and rapid escalation of risk incidents, issues and concerns. These practices are likely to enhance low ESI climate, triggering actions that are likely to diminish UPB. Proactive climate supports employees by guiding them how to act appropriately on any concerns they may have, flowing from the ill-treatment of external stakeholders.

Similarly, where managers are strong role models and advocates for risk management, employees will be more likely to follow their lead, complying with firm policies themselves and becoming actively engaged in risk management. Low ESI climate is likely to reinforce this relationship, by highlighting when poor customer outcomes might be compromising longer-term organisational goals.

Overall, we expect that the two climates will be complementary. UPB will be lowest when perceptions of ESI are low and when perceptions of risk climate are favourable:

Hypothesis 3a: ESI climate moderates the relationship between avoidance risk climate and UPB, such that the positive relationship is stronger at low as opposed to high levels of ESI climate. 
Hypothesis 3b: ESI climate moderates the relationship between valued and UPB, such that the negative relationship is stronger at low as opposed to high levels of ESI climate.

Hypothesis 3c: ESI climate moderates the relationship between proactive and UPB, such that the negative relationship is stronger at low as opposed to high levels of ESI climate.

Hypothesis 3d: ESI climate moderates the relationship between manager and UPB, such that the negative relationship is stronger at low as opposed to high levels of ESI climate.

\section{Method}

We report on survey responses from employees of three Australian financial institutions. All three are pension funds, or superannuation funds as they are known in Australia. The Australian superannuation industry now manages some A $\$ 2324$ billion in assets (ASFA 2017), making it one of the largest retirement pools in the world. Australian superannuation funds typically operate as trusts, where trustees owe members statutory fiduciary duties as defined in the governing legislation. Like most large funds, the funds participating in this study are prudentially supervised by the Australian Prudential Regulation Authority (APRA). Prudential standards relating to risk management came into effect for superannuation funds in July 2013. These standards highlight the importance of risk climate. APRA expects the board to 'demonstrate its commitment to risk management and foster an environment of active engagement and risk management processes and outcomes, and in which the risk management function is influential and respected' (APRA 2013, paragraph 5). Because of this requirement, the Australian superannuation sector provides an ideal context to investigate the implications of risk climate on unethical behaviour.

Survey data were collected as part of a larger mixedmethods study that included analysis of documents and interviews with senior industry leaders. We chose to present results for three organisations representing a variety of organisational contexts in terms of 'for-profit' versus 'notfor-profit' status and also the extent to which a favourable risk climate is observed. In the results section we highlight statistically significant differences in the risk climate factor scores at the organisational level.

For all samples, employees were surveyed anonymously and were provided a link to the online survey which took around $20 \mathrm{~min}$ to complete. All procedures performed in studies involving human participants were in accordance with the ethical standards of the ethical standards of Macquarie University (approvals 5201300285 and
5201830633436) and the National Statement of Ethical Conduct in Human Research, updated 2018, produced by the Australian Research Council. The three organisations that are the subject of this research each provided informed consent for staff surveys to be conducted. Individual participants were provided with information about the ethical aspects of the research and freely chose whether or not to participate in this anonymous survey. We believe that the variation in response rates is due to variation in the approach taken by management for promoting the survey within their respective organisations.

Sample 1 'not-for-profit': We received 167 complete survey responses and the response rate was $74 \%$. Respondents were $52 \%$ male, with average age and tenure of 43.4 and 9.7 years, respectively. Most (60\%) were non-managerial employees.

Sample 2 'not-for-profit': We received 319 complete survey responses and the response rate was $50 \%$. Respondents were $46 \%$ male, with average age and tenure of 39.2 and 5.4 years, respectively. Most (76\%) were non-managerial employees.

Sample 3 'for-profit': We received 191 complete survey responses and the response rate was $14 \%$. Respondents were $53 \%$ male, with average age and tenure of 38.7 and 6.9 years, respectively. Most (58\%) were non-managerial employees.

\section{Measures}

Established scales were used to measure the study variables. Unless otherwise specified, a 6-point Likert scale was used to assess the substantive variables $(1=$ strongly disagree; $6=$ strongly agree). Items were coded such that a higher score represented a greater amount of the focal construct, with the exception of reverse-coded items. Our measures of climate are based on individual perceptions, or psychological climate. This approach is consistent with the majority of ethical climate research (Trevino et. al. 2014), and the fact that our outcome measure, UPB, is a measure of individual behaviour. In multilevel theory, individual behaviours and attitudes are, in the first instance, an outcome of psychological climate (Ostroff et al. 2012).

\section{Risk Climate}

Individual perceptions of risk climate were assessed using 18 items with four factors from Sheedy et al. (2017). The first factor, avoidance, has six items and captures perceptions of the tendency within the organisation to ignore or avoid employees' questions about risk taking and acceptable risk. A sample item is "senior leaders don't want to hear about bad news". The second factor, valued, comprises four items and represents the degree to which risk management and risk 
managers were valued and respected throughout the organisation. A sample item is "risk managers have authority and status in this organisation". The third factor, proactive, comprises five items that measure whether practices to actively address risk are present in the organisation. A sample item is "for us, analysing risk events is very useful". Lastly, the factor called manager comprises three items representing the degree to which managers encourage and role model appropriate risk management behaviour. A sample items is "when it comes to managing risk, my manager is an excellent role model of desirable behavior".

Prior coefficient alphas for the scales range from 0.69 to 0.92 (Sheedy et al. 2017). Valued $(\beta=0.04, p<0.01)$, proactive $(\beta=0.33, p<0.001)$ and manager $(\beta=0.15, p<0.001)$ subscales were found to significantly predict positive risk behaviour providing evidence of convergent validity (Sheedy et al. 2017). In this study, we obtained excellent Cronbach's alpha reliabilities for avoidance (Sample $1 \alpha=0.84$; Sample $2 \alpha=0.83$; Sample $3 \alpha=0.87$ ), valued (Sample $1 \alpha=0.84$; Sample $2 \alpha=0.84$; Sample $3 \alpha=0.87$ ), proactive (Sample 1 $\alpha=82$; Sample $2 \alpha=0.80$; Sample $3 \alpha=0.84$ ) and manager (Sample $1 \alpha=0.91$; Sample $2 \alpha=0.91$; Sample $3 \alpha=0.93$ ) across all samples.

\section{Ethical Self-interest (ESI) Climate}

This climate was measured using three items from the scale developed by Arnaud and Schminke (2012). It measures the extent to which individuals perceive people in their organisation are primarily guided by self-interest and personal benefits. Items are: "People around here are mostly out for themselves; People in my business unit think of their own welfare first when faced with a difficult decision; In my business unit, people's primary concern is their own personal benefit". We obtained excellent Cronbach's alpha reliabilities across samples (Sample $1 \alpha=0.94$; Sample $2 \alpha=0.94$; Sample $3 \alpha=0.95$ ).

\section{Unethical Pro-organisational Behaviours}

UPB was measured using the scale developed by Umphress et al. (2010). The scale measures a respondent's willingness to engage in UPB via a Likert type scale. Due to space constraints imposed by participating organisations, we used a short version of the scale and chose the top three items with the highest factor loadings. The items for this scale are: "I would misrepresent the truth to make my organisation look good", "If it would help my organisation, I would exaggerate the truth about my company's products or services to members" and "If it would help my organisation, I would misrepresent the truth to make my organisation look good". We obtained good Cronbach's alpha reliabilities (Sample 1 $\alpha=0.91$; Sample $2 \alpha=0.78$; Sample $3 \alpha=0.84$ ).

\section{Control Variables}

We controlled for employee age and gender as meta-analytic findings revealed a correlation between these variables and unethical choices (Kish-Gephart et al. 2010). Responses to our study variables may be prone to attempts at impression management given its sensitive nature. Indeed, prior work has shown a correlation between socially desirable responding and unethical decision-making (Chung and Monroe 2003). As such, we controlled for impression management (Sample $1 \alpha=0.64$; Sample $2 \alpha=0.70$; Sample $3 \alpha=0.71$ ), measured with six items from Hart et al. (2015).

\section{Results}

We conducted confirmatory factor analyses (CFA) to examine the discriminant validity of the four dimensions of risk climate, plus ESI and UPB. The six-factor model demonstrated acceptable fit in Sample 1 (Root Mean Square Error of Approximation (RMSEA) $=0.05$, Confirmatory Fit Index $(\mathrm{CFI})=0.94$, Tucker-Lewis Index $(\mathrm{TLI})=0.93)$, Sample $2($ RMSEA $=0.06, \mathrm{CFI}=0.97, \mathrm{TLI}=0.96)$ and Sample 3 $(\mathrm{RMSEA}=0.04, \mathrm{CFI}=0.98, \mathrm{TLI}=0.98)$. We compared this six-factor model with a three-factor model where all risk climate dimensions were combined into one factor with ESI and UPB as separate factors, and a two-factor model where all four risk culture factors were combined into one factor and ESI and UPB combined into another factor. The chi-square difference tests revealed that the six-factor model offered the best fit.

Descriptive statistics and zero-order correlations for all study variables in Samples 1, 2 and 3 are summarised in Tables 1, 2 and 3, respectively. The sample means for each of our climate measures are worthy of discussion since they show that the three organisations have different workplace climates. Not-for-profit samples 1 and 2 are not as self-interested as for-profit sample 3, as reflected in the mean scores for ESI climate (difference $=-0.34, p=0.001$ ). Sample 2 has the most favourable (lowest) score for avoidance risk climate, significantly lower than either sample $1(p=0.05)$ or sample $3(p=0.001)$. Sample 2 also has the most favourable (highest) score for valued risk climate, significantly higher than either sample $1(p<0.001)$ or sample $3(p<0.001)$. Similarly, sample 2 has the most favourable (highest) score for proactive risk climate, significantly higher than either sample $1(p<0.001)$ or sample $3(p<0.001)$. Finally, samples 1 and 2 have more favourable (higher) scores for manager risk climate, significantly higher than sample 3 $(p<0.001)$.

Our results are reported separately for each sample as this provides additional information regarding the consistency and overall pattern of results. That is, each sample can be 
Table 1 Means, standard deviations and zero-order correlations of study variables in Sample 1

\begin{tabular}{|c|c|c|c|c|c|c|c|c|c|c|}
\hline Variables & $M$ & $S D$ & 1 & 2 & 3 & 4 & 5 & 6 & 7 & 8 \\
\hline \multicolumn{11}{|l|}{ Sample $1(N=167)$} \\
\hline 1. Age & 43.42 & 11.49 & & & & & & & & \\
\hline 2. Gender & .49 & .50 & $-.16^{*}$ & & & & & & & \\
\hline 3. Impression management & 4.98 & .64 & .07 & .06 & & & & & & \\
\hline 4. Avoidance & 2.58 & .85 & -.02 & .10 & $-.28 * * *$ & & & & & \\
\hline 5. Valued & 4.52 & .82 & .03 & -.11 & .12 & $-.61 * * *$ & & & & \\
\hline 6. Proactive & 4.75 & .78 & .03 & .03 & .14 & $-.45^{* * *}$ & $.54 * * *$ & & & \\
\hline 7. Manager & 5.33 & .77 & -.03 & .06 & .02 & $-.52 * * *$ & $.31 * * *$ & $.47 * * *$ & & \\
\hline 8. Ethical self-interest (ESI) climate & 2.12 & 1.04 & .07 & -.01 & $-.25 * *$ & $.55^{* * *}$ & $-.42 * * *$ & $-.40 * * *$ & $-.44 * * *$ & \\
\hline $\begin{array}{l}\text { 9. Unethical pro-organisational } \\
\text { behaviour (UPB) }\end{array}$ & 1.46 & .74 & -.04 & .06 & -.08 & $.22 * *$ & -.03 & -.01 & $-.18^{*}$ & $.31 * * *$ \\
\hline
\end{tabular}

Table 2 Means, standard deviations and zero-order correlations of study variables in Sample 2

\begin{tabular}{|c|c|c|c|c|c|c|c|c|c|c|}
\hline Variables & $M$ & $S D$ & 1 & 2 & 3 & 4 & 5 & 6 & 7 & 8 \\
\hline \multicolumn{11}{|l|}{ Sample $2(N=319)$} \\
\hline 1. Age & 39.20 & 9.07 & & & & & & & & \\
\hline 2. Gender & .54 & .50 & -.07 & & & & & & & \\
\hline 3. Impression management & 4.99 & .68 & $.19 * *$ & .01 & & & & & & \\
\hline 4. Avoidance & 2.42 & .90 & -.02 & -.03 & $-.29 * * *$ & & & & & \\
\hline 5. Valued & 4.95 & .74 & -.06 & .04 & .08 & $-.58 * * *$ & & & & \\
\hline 6. Proactive & 5.04 & .75 & .01 & .05 & $.17 * *$ & $-.49 * * *$ & $.49 * * *$ & & & \\
\hline 7. Manager & 5.35 & .73 & .07 & -.04 & $.30 * * *$ & $-.44 * * *$ & $.39 * * *$ & $.51 * * *$ & & \\
\hline 8. Ethical self-interest (ESI) climate & 2.12 & 1.09 & -.07 & .05 & $-.35 * * *$ & $.55^{* * *}$ & $-.39 * * *$ & $-.43 * * *$ & $-.45 * * *$ & \\
\hline $\begin{array}{l}\text { 9. Unethical pro-organisational } \\
\text { behaviour (UPB) }\end{array}$ & 1.60 & .72 & $-.12 *$ & -.06 & $-.28 * * *$ & $.34 * * *$ & -.05 & $-.15^{* *}$ & $-.22 * * *$ & $.29 * * *$ \\
\hline
\end{tabular}

$* p<.05$

$* * p<.01$

$* * * p<.001$

thought of as providing evidence of replication (or not) for each of our hypotheses in heterogeneous samples.

To test hypotheses we conducted a series of hierarchical multiple regressions to assess the incremental explanatory power of variables in each block (Aiken and West 1991). First, we examined the relationship between control variables and UPB, or more accurately, willingness to engage in UPB. Throughout the results section, we use the term 'UPB' to mean 'willingness to engage in UPB' to simplify the exposition and aid readability. As model 1 shows, impression management significantly predicted UPB in Samples $2(\beta=-0.26, p<0.001)$ and $3(\beta=-0.21$, $p<0.001)$.

Second, we conducted single climate analyses, entering the four dimensions of risk climate and ESI climate to test for our main effect hypotheses (H1a to H1d and H2). To avoid possible issues with multi-collinearity and hence interpretation of the coefficients, we entered the risk climate factors in separate regressions. Results for each hypothesis test are presented in models 2-6 of Tables 4, 5 and 6, controlling for age, gender and impression management.

Avoidance risk climate (model 2) is significantly associated with UPB in all three samples (Sample $1 \beta=0.21$, $p<0.01$; Sample $2 \beta=0.28, p<0.001$; Sample $3 \beta=0.18$, $p<0.05)$. H1a is supported.

Valued risk climate (model 3) is not significantly associated with UPB in any of the three samples. H1b is not supported. 
Table 3 Means, standard deviations and zero-order correlations of study variables in Sample 3

\begin{tabular}{|c|c|c|c|c|c|c|c|c|c|c|}
\hline Variables & $M$ & $S D$ & 1 & 2 & 3 & 4 & 5 & 6 & 7 & 8 \\
\hline \multicolumn{11}{|l|}{ Sample $3(N=191)$} \\
\hline 1. Age & 38.68 & 10.37 & & & & & & & & \\
\hline 2. Gender & .47 & .50 & .09 & & & & & & & \\
\hline 3. Impression management & 4.91 & .69 & $.17 *$ & .11 & & & & & & \\
\hline 4. Avoidance & 2.83 & .98 & $.16^{*}$ & -.03 & $-.16^{*}$ & & & & & \\
\hline 5. Valued & 4.30 & .91 & .01 & .04 & $.17 *$ & $-.55 * * *$ & & & & \\
\hline 6. Proactive & 4.52 & .89 & -.04 & -.01 & .13 & $-.62 * * *$ & $.46^{* * *}$ & & & \\
\hline 7. Manager & 4.95 & 1.03 & -.06 & -.04 & .08 & $-.57 * * *$ & $.43 * * *$ & $.50 * * *$ & & \\
\hline 8. Ethical self-interest (ESI) climate & 2.46 & 1.19 & -.08 & .05 & $-.14^{*}$ & $.52 * * *$ & $-.25 * * *$ & $-.41 * * *$ & $-.39 * * *$ & \\
\hline $\begin{array}{l}\text { 9. Unethical pro-organisational } \\
\text { behaviour (UPB) }\end{array}$ & 1.97 & .88 & -.10 & -.04 & $-.22 * *$ & $.19 * *$ & -.01 & $-.23 * *$ & .01 & $.26 * * *$ \\
\hline
\end{tabular}

Table 4 Results of single climate regression analyses in Sample $1^{\mathrm{a}}$ with UPB as dependent variable

\begin{tabular}{|c|c|c|c|c|c|c|}
\hline \multirow[t]{2}{*}{ Variables } & \multirow{2}{*}{$\begin{array}{l}\text { Control } \\
\text { Model } \\
1\end{array}$} & \multicolumn{5}{|c|}{ Main effects } \\
\hline & & $\begin{array}{l}\text { Model } \\
2\end{array}$ & $\begin{array}{l}\text { Model } \\
3\end{array}$ & $\begin{array}{l}\text { Model } \\
4\end{array}$ & $\begin{array}{l}\text { Model } \\
5\end{array}$ & Model 6 \\
\hline \multicolumn{7}{|l|}{ Control variables } \\
\hline Age & -.02 & -.03 & -.02 & -.02 & -.03 & -.05 \\
\hline Gender & .06 & .03 & .06 & .06 & .07 & .06 \\
\hline Impression management & -.08 & -.02 & -.08 & -.07 & -.08 & -.01 \\
\hline \multicolumn{7}{|l|}{ Main effects } \\
\hline Avoidance & & $.21 * *$ & & & & \\
\hline Valued & & & -.02 & & & \\
\hline Proactive & & & & -.09 & & \\
\hline Manager & & & & & $-.19^{*}$ & \\
\hline Ethical self-interest (ESI) climate & & & & & & $.31 * * *$ \\
\hline$R^{2}$ & .01 & .05 & .01 & .02 & .05 & .10 \\
\hline$\Delta R^{2}$ & & .04 & .00 & .01 & .04 & .09 \\
\hline$F$ & .59 & 2.19 & .45 & .78 & 1.96 & $4.55^{* *}$ \\
\hline $\begin{array}{l}{ }^{\mathrm{a}} n=167 . \text { Standardised coefficients a } \\
{ }^{*} p<.05 \\
{ }^{* *} p<.01 \\
{ }^{* * * *} p<.001\end{array}$ & reported & & & & & \\
\hline
\end{tabular}

Proactive risk climate (model 4 ) is significantly associated with UPB only in Sample $3(\beta=-0.21, p<0.01)$. H1c is partially supported.

Manager risk climate (model 5) is significantly associated with UPB in two samples (Sample $1 \beta=-0.19, p<0.05$; Sample $2 \beta=-0.15, p<0.01)$. H1d is partially supported.

ESI climate (model 6) is significantly associated with UPB in all three samples (Sample $1 \beta=0.31, p<0.001$; Sample $2 \beta=0.23, p<0.001$; Sample $3 \beta=0.24, p<0.01$ ). $\mathrm{H} 2$ is supported.
The final step was multi-climate analysis which is presented in Tables 7-9. Here each of the risk climate factors were separately combined with ESI climate. Models 2-5 in these tables show that the risk climate factors were generally not significantly associated with UPB after controlling both for control variables and ESI climate. The only exception to this pattern was avoidance in Sample 2, the sample with the highest average score for avoidance risk climate $(\beta=0.23$, $p<0.01)$. This suggests that risk climate does not generally explain any additional variance over and above ESI climate. 
Table 5 Results of single climate regression analyses in Sample $2^{\mathrm{a}}$ with UPB as dependent variable

\begin{tabular}{|c|c|c|c|c|c|c|}
\hline \multirow[t]{2}{*}{ Variables } & \multirow{2}{*}{$\begin{array}{l}\text { Control } \\
\text { Model } \\
1\end{array}$} & \multicolumn{5}{|c|}{ Main effects } \\
\hline & & $\begin{array}{l}\text { Model } \\
2\end{array}$ & $\begin{array}{l}\text { Model } \\
3\end{array}$ & $\begin{array}{l}\text { Model } \\
4\end{array}$ & $\begin{array}{l}\text { Model } \\
5\end{array}$ & Model 6 \\
\hline \multicolumn{7}{|l|}{ Control variables } \\
\hline Age & -.08 & -.09 & -.08 & -.08 & -.08 & -.08 \\
\hline Gender & -.06 & -.05 & -.06 & -.05 & -.06 & -.07 \\
\hline Impression management & $-.26 * * *$ & $-.18^{* *}$ & $-.26 * * *$ & $-.25^{*}$ & $-.22 * * *$ & $-.19 * *$ \\
\hline \multicolumn{7}{|l|}{ Main effects } \\
\hline Avoidance & & $.28 * * *$ & & & & \\
\hline Valued & & & -.03 & & & \\
\hline Proactive & & & & -.11 & & \\
\hline Manager & & & & & $-.15^{* *}$ & \\
\hline Ethical self-interest (ESI) climate & & & & & & $.23 * * *$ \\
\hline$R^{2}$ & .09 & .16 & .09 & .10 & .11 & .13 \\
\hline$\Delta R^{2}$ & & .07 & .00 & .01 & .02 & .04 \\
\hline$F$ & $9.96 * * * *$ & $14.92 * * *$ & $7.54 * * *$ & $8.49 * * *$ & $9.49 * * *$ & $11.90 * * *$ \\
\hline $\begin{array}{l}{ }^{\mathrm{a}} n=319 . \text { Standardised coefficients } \\
{ }^{*} p<.05 \\
{ }^{* *} p<.01 \\
{ }^{* * * *} p<.001\end{array}$ & re reported & & & & & \\
\hline
\end{tabular}

Table 6 Results of single climate regression analyses in Sample $3^{\mathrm{a}}$ with UPB as dependent variable

\begin{tabular}{|c|c|c|c|c|c|c|}
\hline \multirow[t]{2}{*}{ Variables } & \multirow{2}{*}{$\begin{array}{l}\text { Control } \\
\text { Model } \\
1\end{array}$} & \multicolumn{5}{|c|}{ Main effects } \\
\hline & & $\begin{array}{l}\text { Model } \\
2\end{array}$ & $\begin{array}{l}\text { Model } \\
3\end{array}$ & $\begin{array}{l}\text { Model } \\
4\end{array}$ & $\begin{array}{l}\text { Model } \\
5\end{array}$ & Model 6 \\
\hline \multicolumn{7}{|l|}{ Control variables } \\
\hline Age & -.06 & -.10 & -.06 & -.07 & -.06 & -.05 \\
\hline Gender & -.01 & -.01 & -.01 & -.01 & -.01 & -.03 \\
\hline Impression management & $-.21 * *$ & $-.18 *$ & $-.22 * *$ & $-.18^{*}$ & $-.21 * *$ & -.18 \\
\hline \multicolumn{7}{|l|}{ Main effects } \\
\hline Avoidance & & $.18^{*}$ & & & & \\
\hline Valued & & & .03 & & & \\
\hline Proactive & & & & $-.21 * *$ & & \\
\hline Manager & & & & & .02 & \\
\hline Ethical self-interest (ESI) climate & & & & & & $.24 * *$ \\
\hline$R^{2}$ & .05 & .08 & .05 & .10 & .05 & .11 \\
\hline$\Delta R^{2}$ & & .03 & .00 & .05 & .00 & .06 \\
\hline$F$ & $3.50 *$ & $4.17 * *$ & 2.65 & $4.99 * *$ & 2.64 & $5.61 * * *$ \\
\hline
\end{tabular}

${ }^{a} n=191$. Standardised coefficients are reported

${ }^{*} p<.05$

*** $p<.01$

*** $p<.001$
After controlling for individual risk climate factors, ESI climate was consistently associated with UPB across all samples except when it was entered with avoidance in Sample $2(\beta=0.11, n . s$.). This provides further evidence in support of $\mathrm{H} 2$.

Finally, we examined whether the relationships between each of the four factors of risk climate and UPB was moderated by ESI climate. Models 6 to 9 in Tables 7, 8 and 9 tested each interaction term separately. We proposed in $\mathrm{H} 3 \mathrm{a}$ that the relationship between avoidance and UPB was moderated by ESI climate. As shown in model 6 of Tables 7, 8 and 9 , the interaction term avoidance $\times$ ESI was significantly associated with UPB in Samples $2(\beta=-0.19, p<0.01)$ and $3(\beta=-0.20, p<0.05)$. To assess whether the form of this 
Table 7 Results of multiple-climate regression analyses in Sample $1^{\text {a }}$ dependent variable is UPB

\begin{tabular}{|c|c|c|c|c|c|c|c|c|c|}
\hline \multirow[t]{2}{*}{ Variables } & \multirow{2}{*}{$\begin{array}{l}\text { Control } \\
\text { Model } \\
1\end{array}$} & \multicolumn{4}{|c|}{ Main effects } & \multicolumn{4}{|c|}{ Moderation } \\
\hline & & $\begin{array}{l}\text { Model } \\
2\end{array}$ & $\begin{array}{l}\text { Model } \\
3\end{array}$ & $\begin{array}{l}\text { Model } \\
4\end{array}$ & $\begin{array}{l}\text { Model } \\
5\end{array}$ & $\begin{array}{l}\text { Model } \\
6\end{array}$ & $\begin{array}{l}\text { Model } \\
7\end{array}$ & $\begin{array}{l}\text { Model } \\
8\end{array}$ & $\begin{array}{l}\text { Model } \\
9\end{array}$ \\
\hline \multicolumn{10}{|l|}{ Control variables } \\
\hline Age & -.02 & -.05 & -.06 & -.05 & -.05 & -.05 & -.07 & -.05 & -.04 \\
\hline Gender & .06 & .05 & .07 & .05 & .06 & .05 & .08 & .05 & .08 \\
\hline Impression management & -.08 & .01 & -.01 & -.01 & -.01 & .01 & .01 & .01 & -.01 \\
\hline \multicolumn{10}{|l|}{ Main effects } \\
\hline Avoidance & & .06 & & & & .07 & & & \\
\hline Valued & & & .13 & & & & .09 & & \\
\hline Proactive & & & & .03 & & & & -.02 & \\
\hline Manager & & & & & -.07 & & & & -.14 \\
\hline Ethical self-interest (ESI) climate & & $.28 * *$ & $.37 * * *$ & $.32 * * *$ & $.28 * *$ & $.29 * *$ & $.47 * * *$ & $.37 * * *$ & $.29 * *$ \\
\hline \multicolumn{10}{|l|}{ Interactions } \\
\hline Avoidance $\times$ ESI & & & & & & -.04 & & & \\
\hline Valued $\times$ ESI & & & & & & & $.25^{* *}$ & & \\
\hline Proactive $\times$ ESI & & & & & & & & $.24 * *$ & \\
\hline Manager $\times$ ESI & & & & & & & & & .16 \\
\hline$R^{2}$ & .01 & .10 & .11 & .10 & .10 & .10 & .16 & .15 & .12 \\
\hline$\Delta R^{2}$ & & .09 & .10 & .09 & .09 & .09 & .05 & .05 & .02 \\
\hline$F$ & .59 & $3.73 * *$ & $4.16^{* *}$ & $3.65^{* *}$ & $3.77 * *$ & $3.12 * *$ & $5.22 * * *$ & $4.74 * * *$ & $3.81 * *$ \\
\hline
\end{tabular}

and other interactions is consistent with our hypotheses, we plotted the interactions according to the guidelines provided by Aitken and West (1991). As shown in Figs. 2 and 3 , the relationship between avoidance and UPB when ESI climate is high versus low is in the predicted direction. That is, the positive relationship between avoidance and UPB was strongest when ESI climate was low. Overall, H3a was partially supported.

Hypothesis $3 \mathrm{~b}$ predicted that the relationship between valued and UPB is moderated by ESI climate. As shown in model 7 in Tables 7, 8 and 9, the valued and ESI interaction was significantly associated with UPB across all samples (Sample $1 \beta=0.25, p<0.01$; Sample $2 \beta=0.19$, $p<0.01$; Sample $3 \beta=0.21, p<0.01)$. As shown in Figs. 4 , 5 and 6 , the relationship between valued and UPB when ESI climate is low is in the predicted direction. However, when ESI climate is high, the relationship between valued and UPB switches to positive. These findings are puzzling, but consistent with similar findings in Sheedy and Griffin 2018, which link valued to negative risk behaviour (see Table 7 and related discussion). It suggests that the items in the valued factor may not be measuring what they purport to measure, possibly because employees have difficulty in distinguishing between espoused and genuine values. The results in this sample are still, however, consistent with our prediction that the negative relationship between valued and UPB is stronger at low as opposed to high levels of ESI climate. Overall, H3b was supported.

Hypothesis $3 \mathrm{c}$ predicted that the relationship between proactive and UPB is moderated by ESI climate. As shown in model 8 in Tables 7, 8 and 9, the proactive and ESI interaction was significantly associated with UPB across all samples (Sample $1 \beta=0.24, p<0.01$; Sample 2 $\beta=0.19, p<0.01$; Sample $3 \beta=0.17, p<0.05)$. As shown in Figs. 7, 8 and 9, the relationship between proactive and UPB when ESI is high versus low is in the predicted direction. Overall, H3c was supported.

Hypothesis $3 \mathrm{~d}$ predicted that the relationship between manager and UPB is moderated by ESI climate. As shown in model 9 in Tables 7, 8 and 9, the manager and ESI interaction was significantly associated with UPB in Samples 2 $(\beta=0.30, p<0.001)$ and $3(\beta=0.20, p<0.05)$. As shown in Figs. 10 and 11, the relationship between manager and UPB when ESI is high versus low is in the predicted direction. Overall, H3d was partially supported.

Table 10 summarises the results of all hypotheses across the three samples, showing both regression coefficients and significance levels. 
Table 8 Results of multiple-climate regression analyses in Sample $2^{\mathrm{a}}$ Dependent Variable is UPB

\begin{tabular}{|c|c|c|c|c|c|c|c|c|c|}
\hline \multirow[t]{2}{*}{ Variables } & \multirow{2}{*}{$\begin{array}{l}\text { Control } \\
\text { Model } \\
1\end{array}$} & \multicolumn{4}{|c|}{ Main effects } & \multicolumn{4}{|c|}{ Moderation } \\
\hline & & $\begin{array}{l}\text { Model } \\
2\end{array}$ & $\begin{array}{l}\text { Model } \\
3\end{array}$ & $\begin{array}{l}\text { Model } \\
4\end{array}$ & $\begin{array}{l}\text { Model } \\
5\end{array}$ & $\begin{array}{l}\text { Model } \\
6\end{array}$ & $\begin{array}{l}\text { Model } \\
7\end{array}$ & $\begin{array}{l}\text { Model } \\
8\end{array}$ & $\begin{array}{l}\text { Model } \\
9\end{array}$ \\
\hline \multicolumn{10}{|l|}{ Control variables } \\
\hline Age & -.08 & -.09 & -.07 & -.08 & -.08 & -.08 & -.08 & -.07 & -.06 \\
\hline Gender & -.06 & -.06 & -.08 & -.07 & -.07 & -.06 & -.07 & -.06 & -.05 \\
\hline Impression management & $-.26 * * *$ & $-.16^{* *}$ & $-.18 * *$ & $-.18 * *$ & $-.20 * *$ & $.16^{* *}$ & $-.16^{* *}$ & $-.19 * *$ & $-.20 * *$ \\
\hline \multicolumn{10}{|l|}{ Main effects } \\
\hline Avoidance & & $.23 * * *$ & & & & $.25 * * *$ & & & \\
\hline Valued & & & .06 & & & & .03 & & \\
\hline Proactive & & & & -.02 & & & & -.08 & \\
\hline Manager & & & & & -.08 & & & & $-.21 * *$ \\
\hline Ethical self-interest (ESI) climate & & .11 & $.25 * * *$ & $.22 * * *$ & $.20 * *$ & $.19 * *$ & $.32 * * *$ & $.27 * * *$ & $.24 * * *$ \\
\hline \multicolumn{10}{|l|}{ Interactions } \\
\hline Avoidance $\times$ ESI & & & & & & $-.19 * *$ & & & \\
\hline Valued $\times$ ESI & & & & & & & $.19 * *$ & & \\
\hline Proactive $\times$ ESI & & & & & & & & $.19 * *$ & \\
\hline Manager $\times$ ESI & & & & & & & & & $.30 * * *$ \\
\hline$R^{2}$ & .09 & .17 & .14 & .13 & .14 & .20 & .16 & .16 & .20 \\
\hline$\Delta R^{2}$ & & .08 & .05 & .05 & .05 & .03 & .03 & .03 & .06 \\
\hline$F$ & $9.96 * * *$ & $12.61 * * *$ & $9.75 * * *$ & $9.52 * * *$ & $9.90 * * *$ & $12.63 * * *$ & $10.15^{* * *}$ & $10.00 * * *$ & $12.74 * * *$ \\
\hline $\begin{array}{l}{ }^{a} n=319 . \text { Standardised coefficients } \\
{ }^{*} p<.05 \\
{ }^{* *} \quad p<.01 \\
{ }^{* * *} p<.01\end{array}$ & reported & & & & & & & & \\
\hline
\end{tabular}

As a robustness check, we tested the model again without control variables. In all samples, we observed no differences in results for the interaction tests. Bootstrapped confidence intervals were also consistent with the obtained p-values for all regression coefficients.

As a further check of Hypothesis 2, we confirmed the robustness of ESI climate to the inclusion of all four risk climate factors simultaneously (Sample 1: $\beta=0.30$, $p=0.01$; Sample 2: $\beta=0.17, p=0.05$; Sample 3: $\beta=0.24$, $p=0.01$ ).

Furthermore, we tested for the potential presence of common method variance (CMV) using Harman's one-factor test (Podsakoff et al. 2003). The test revealed that a single factor explained $33-35 \%$ of the variance across all samples, well below the threshold of 50\% (Podsakoff et al. 2003). Indeed, a recent simulation study revealed that a single factor needs to explain at least $70 \%$ or more before any substantial concerns about inflated relationships between the study variables would arise (Fuller et al. 2016). This, in addition to the significant interaction effects and the inclusion of impression management as a control variable, mitigates CMV concerns in this study.

\section{Discussion, Implications, Limitations and Conclusion}

The study sheds new light on the work environment most likely to inhibit UPB, an important issue with significant implications across industries. In three financial services organisational samples, we investigated two distinct focused climates: multi-factor risk climate and ESI climate. Our measure of UPB, consistent with previous literature, is framed as willingness to engage in conduct that is harmful to external stakeholders, for the benefit of the organisation.

When considered in isolation, both risk climate (avoidance) and ESI climate are consistently relevant for explaining potential UPB. When considered in a multi-climate framework, however, the picture is more complex. This demonstrates the value of multi-climate research, a relatively new theoretical focus for organisational studies. The relationship between each of three risk climate factors (avoidance, proactive and manager) and UPB is moderated by ESI climate. A favourable (low) ESI climate enables risk climate to exert a more significant influence on UPB, and without a favourable ESI climate, risk climate loses some of its potency to influence UPB. 
Table 9 Results of multiple-climate regression analyses in Sample $3^{\text {a }}$ Dependent Variable is UPB

\begin{tabular}{|c|c|c|c|c|c|c|c|c|c|}
\hline \multirow[t]{2}{*}{ Variables } & \multirow{2}{*}{$\begin{array}{l}\text { Control } \\
\text { Model } \\
1\end{array}$} & \multicolumn{4}{|c|}{ Main effects } & \multicolumn{4}{|c|}{ Moderation } \\
\hline & & $\begin{array}{l}\text { Model } \\
2\end{array}$ & $\begin{array}{l}\text { Model } \\
3\end{array}$ & $\begin{array}{l}\text { Model } \\
4\end{array}$ & $\begin{array}{l}\text { Model } \\
5\end{array}$ & $\begin{array}{l}\text { Model } \\
6\end{array}$ & $\begin{array}{l}\text { Model } \\
7\end{array}$ & $\begin{array}{l}\text { Model } \\
8\end{array}$ & $\begin{array}{l}\text { Model } \\
9\end{array}$ \\
\hline \multicolumn{10}{|l|}{ Control variables } \\
\hline Age & -.06 & -.06 & -.04 & -.06 & -.04 & -.06 & -.04 & -.07 & -.03 \\
\hline Gender & -.01 & -.02 & -.03 & -.03 & -.03 & -.04 & -.05 & -.03 & -.04 \\
\hline Impression management & $-.21 * *$ & $-.17 *$ & $-.19 * *$ & $-.17 * *$ & $-.18 * *$ & $.16^{*}$ & $-.18^{*}$ & $-.15^{*}$ & $-.18^{*}$ \\
\hline \multicolumn{10}{|l|}{ Main effects } \\
\hline Avoidance & & .07 & & & & .11 & & & \\
\hline Valued & & & .09 & & & & .07 & & \\
\hline Proactive & & & & -.14 & & & & $-.17 *$ & \\
\hline Manager & & & & & -.13 & & & & .05 \\
\hline Ethical self-interest (ESI) climate & & $.20 *$ & $.26 * * *$ & $.18^{*}$ & $.29 * * *$ & $.26 * *$ & $.32 * * *$ & $.23 * *$ & $.34 * * *$ \\
\hline \multicolumn{10}{|l|}{ Interactions } \\
\hline Avoidance $\times$ ESI & & & & & & $-.20^{*}$ & & & \\
\hline Valued $\times$ ESI & & & & & & & $.21 * *$ & & \\
\hline Proactive $\times$ ESI & & & & & & & & $.17 *$ & \\
\hline Manager $\times$ ESI & & & & & & & & & $.20^{*}$ \\
\hline$R^{2}$ & .05 & .11 & .12 & .12 & .12 & .14 & .15 & .15 & .15 \\
\hline$\Delta R^{2}$ & & .06 & .07 & .07 & .07 & .03 & .03 & .03 & .03 \\
\hline$F$ & $3.50^{*}$ & $4.60 * *$ & $4.80 * * *$ & $5.20 * * *$ & $5.15^{* *}$ & $5.00 * * *$ & $5.56 * * *$ & $5.37 * * *$ & $5.42 * * *$ \\
\hline
\end{tabular}

${ }^{\mathrm{a}} n=191$. Standardised coefficients are reported

${ }^{*} p<.05$

${ }^{* *} p<.01$

**** $p<.001$

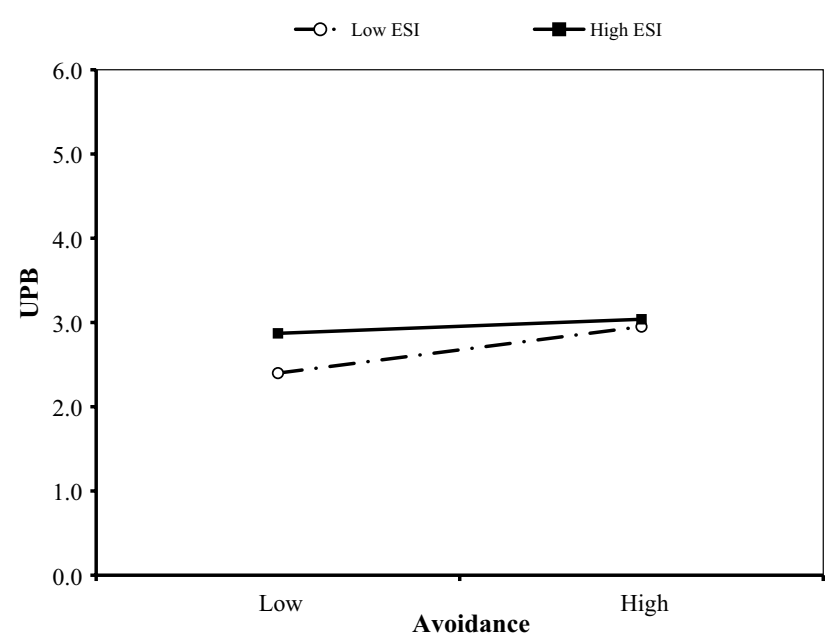

Fig. 2 Plot of the interaction between avoidance and ethical selfinterest climate in predicting UPB in Sample 2

The study highlights the importance of ESI climate, a type of (un)ethical climate, as a potential cause of UPB. We found that ESI climate was associated with potential UPB to a significant extent, regardless of risk climate. This finding suggests that efforts to limit the focus on self and instead

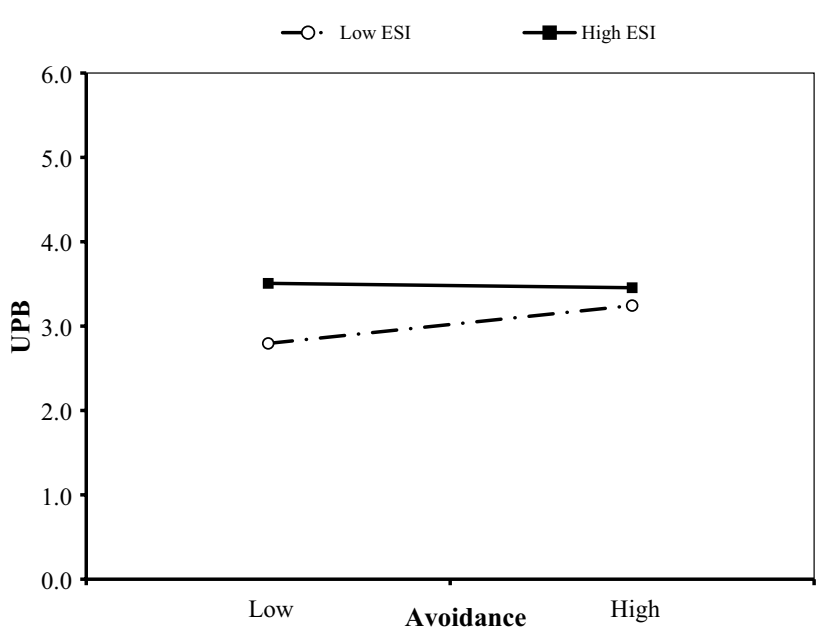

Fig. 3 Plot of the interaction between avoidance and ethical selfinterest climate in predicting UPB in Sample 3

encourage consideration of others, such as customers, will be productive for reducing UPB. The finding is consistent with our understanding of UPB as a behaviour that, while initially benefitting the organisation, is ultimately self-serving. Nevertheless, it represents a significant challenge to the 


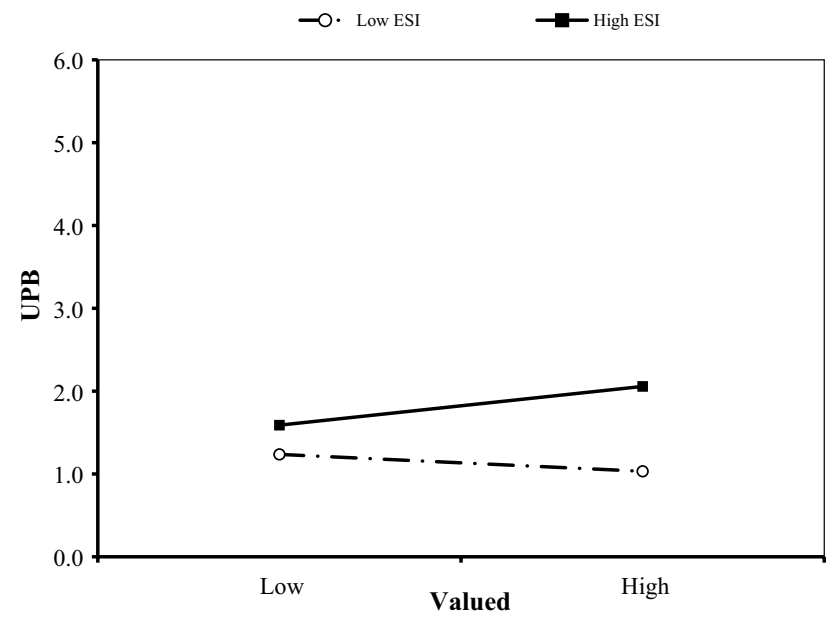

Fig. 4 Plot of the interaction between valued and ethical self-interest climate in predicting UPB in Sample 1

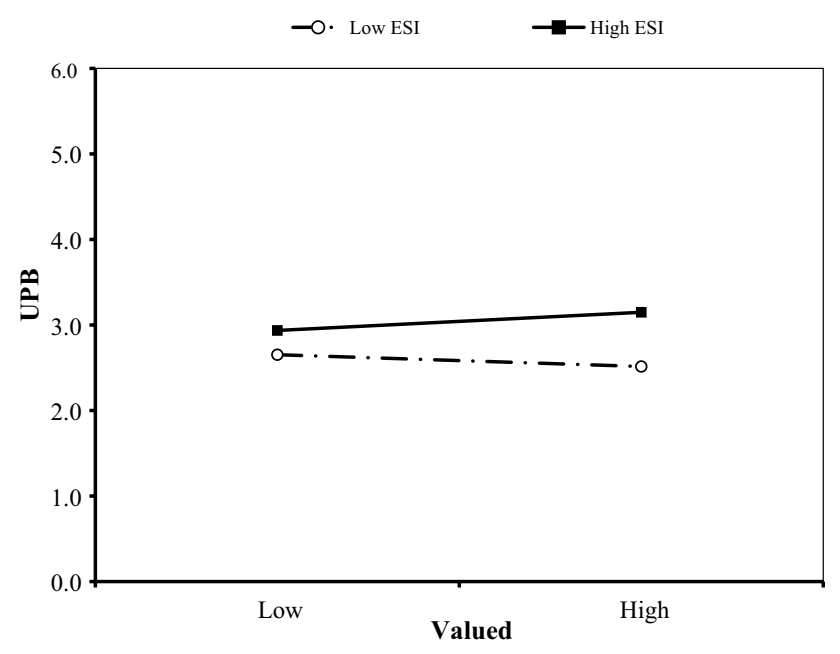

Fig. 5 Plot of the interaction between valued and ethical self-interest climate in predicting UPB in Sample 2

financial services industry, and many others like it, that have traditionally exhibited a high ESI climate.

We found that employees are least likely to report willingness to engage in UPB when they perceive both favourable risk climate and low ESI climate. ESI climate moderates the relationship between three of the risk climate factors and $\mathrm{UPB}$, that is, when ESI climate is low, low avoidance, high proactive and high manager are all associated with reduced UPB.

This new theoretical finding demonstrates how complementary focused climates may inhibit UPB. A favourable risk climate complements ESI climate, presumably because employees will consider the consequences of UPB for both external stakeholders and the organisation itself. Possible harm to multiple stakeholders is likely to be perceived as

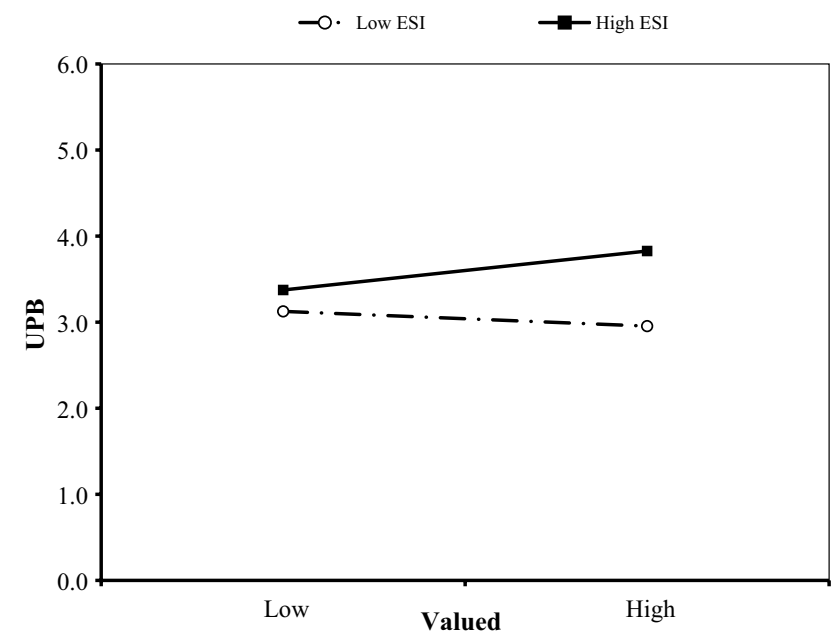

Fig. 6 Plot of the interaction between value and ethical self-interest climate in predicting UPB in Sample 3

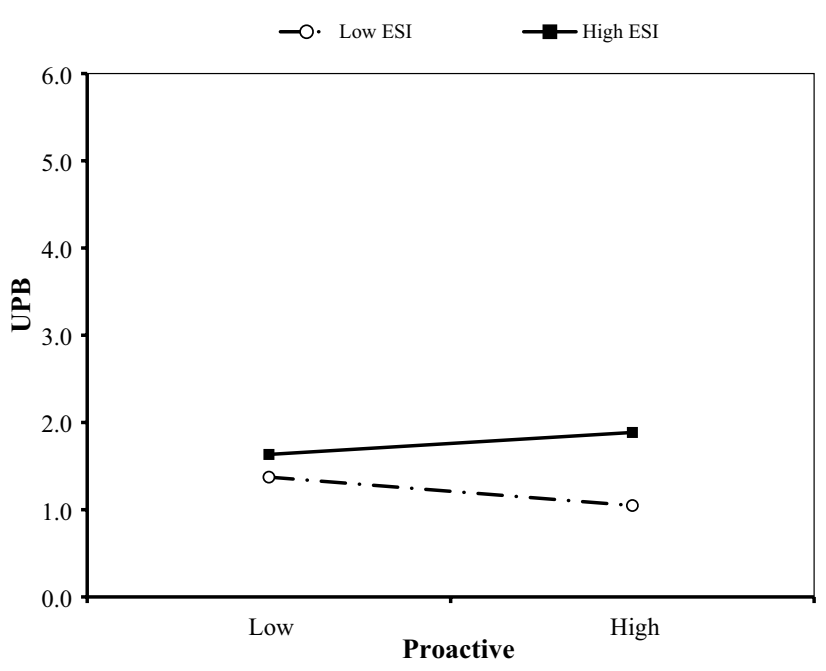

Fig. 7 Plot of the interaction between proactive and ethical self-interest climate in predicting UPB in Sample 1

more impactful than harm to only one stakeholder group. Further, risk climate provides crucial cues as to the appropriate behavioural response to ethical challenges. Risk climate enhances low ESI climate by signalling, for example through the avoidance dimension, that risks to the organisation will not be tolerated, excused or ignored. The proactive risk climate factor guides employees in how to act productively on their ethical concerns. The ability to proactively identify risks to the organisation, to appropriately question work practices, learn from past risk events and escalate issues are all helpful for reducing UPB. Where managers model and consistently communicate the importance of risk management, employees will be less likely to behave in a manner that exploits customers for short-term benefit, ignoring the 


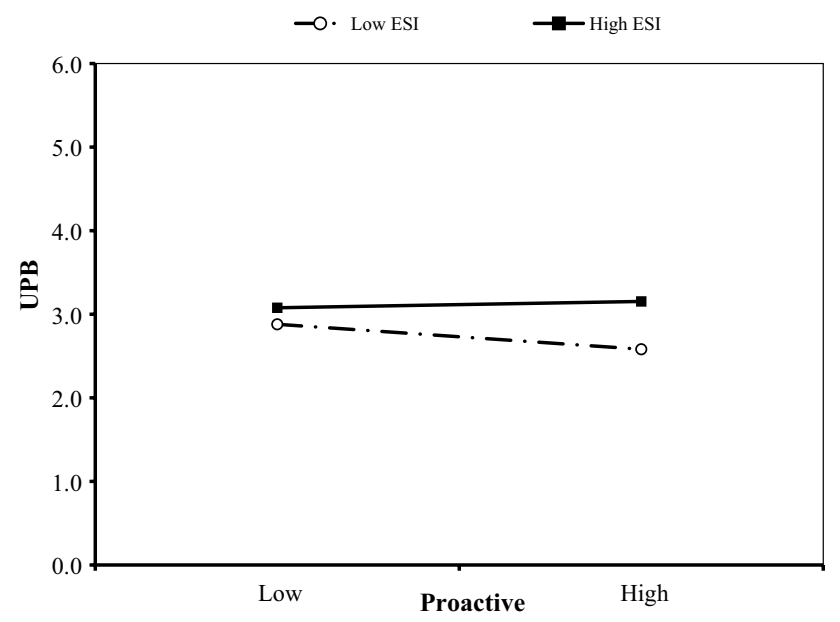

Fig. 8 Plot of the interaction between proactive and ethical self-interest climate in predicting UPB in Sample 2

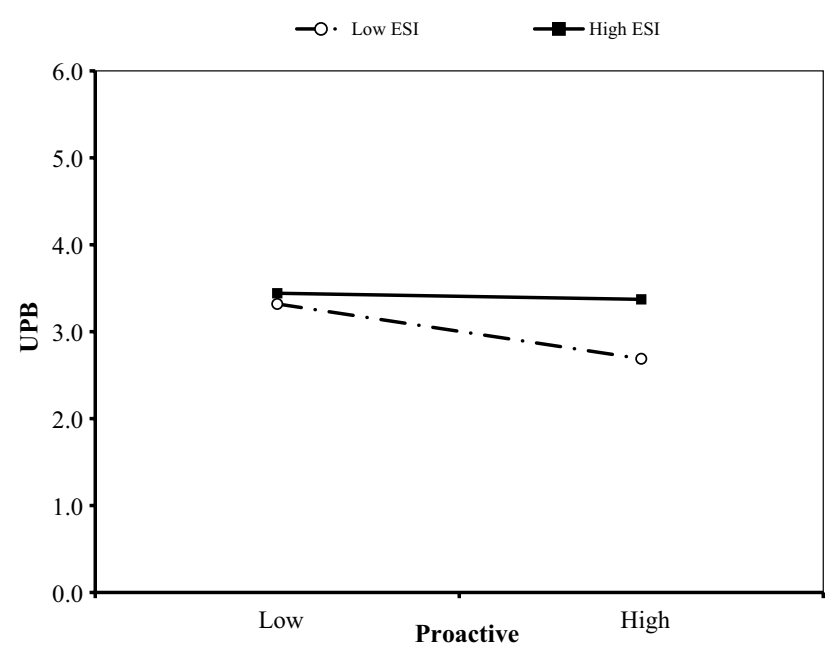

Fig. 9 Plot of the interaction between proactive and ethical self-interest climate in predicting UPB in Sample 3

longer-term consequences for the organisation through fines, remediation programs, legal costs and reputational damage.

Importantly, we found that leaders cannot rely only on instilling risk climate but must also promote low ESI climate if they are to succeed in reducing UPB. One possible explanation for this finding is that attempts to inculcate risk climate have not yet been entirely successful in the Australian context of the study. The challenges of implementing risk climate in large financial institutions have been documented by Palermo, Power and Ashby (2017). The difficulty of shifting from a climate prioritising short-term profits to one that prioritises long-term resilience is perhaps unsurprising in the context of the broader organisational change literature. Keller and Aiken (2009) report only about $30 \%$ of organisational change initiatives succeed. Ehrhart et al. (2013) canvas the

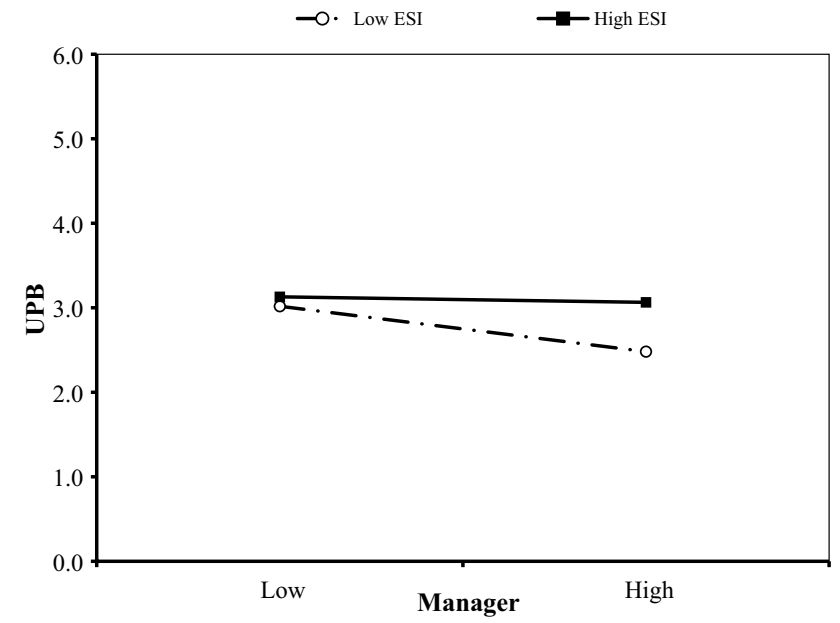

Fig. 10 Plot of the interaction between manager and ethical self-interest climate in predicting UPB in Sample 2

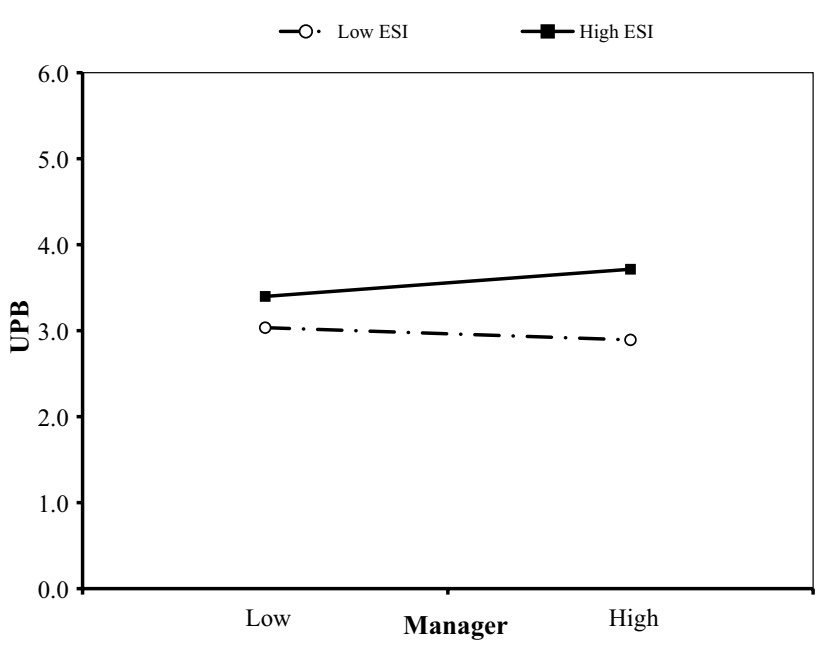

Fig. 11 Plot of the interaction between manager and ethical self-interest climate in predicting UPB in Sample 3

theoretical reasons why organisational environments are so persistent, and change, therefore, is so often problematic. A recent inquiry has found that while existing frameworks for managing financial risks are effective, frameworks for the management of non-financial risks such as misconduct are not sufficiently developed (Royal Commission 2019) and require further attention. The same report highlighted that the Australian regulator has not been sufficiently active in its enforcement activities, creating an environment where consequences of adverse misconduct have not been as significant as they ought to be. As noted previously, risk climate is expected to be most effective for restraining misconduct in well-regulated industries where consequences of adverse misconduct are significant and salient. 
Table 10 Summary of regression coefficients and significance levels in predicting unethical pro-organisational behaviour across samples

\begin{tabular}{|c|c|c|c|c|}
\hline Hypothesis & $\begin{array}{l}\text { Sample } 1 \\
(n=167) \\
\beta\end{array}$ & $\begin{array}{l}\text { Sample } 2 \\
(n=319) \\
\beta\end{array}$ & $\begin{array}{l}\text { Sample } 3 \\
(n=191) \\
\beta\end{array}$ & Conclusion \\
\hline H1a: avoidance & $.21 * *$ & $.28 * * *$ & $.18^{*}$ & Supported \\
\hline H1b: valued & -.02 & -.03 & .03 & Not supported \\
\hline H1c: proactive & -.09 & -.11 & $-.21 * *$ & Partially supported \\
\hline H1d: manager & $-.19 *$ & $-.15 * *$ & .02 & Partially supported \\
\hline H2: ESI climate & $.31 * * *$ & $.23 * * *$ & $.24 * *$ & Supported \\
\hline H3a: avoidance $\times$ ESI & -.04 & $-.19 * *$ & $-.20^{*}$ & Partially supported \\
\hline H3b: valued $\times$ ESI & $.25 * *$ & $.19 * *$ & $.21 * *$ & Supported \\
\hline $\mathrm{H} 3 \mathrm{c}$ : proactive $\times \mathrm{ESI}$ & $.24 * *$ & $.19 * *$ & $.17 *$ & Supported \\
\hline H3d: manager $\times$ ESI & .16 & $.30 * * *$ & $.20 *$ & Partially supported \\
\hline
\end{tabular}

We found few differences in the effects between the three samples, despite the heterogeneity of the organisations, with significance in one sample generally replicated in both other samples. This validation of both the main and interaction effects is encouraging for the generalisability of our findings, especially as our samples exhibit distinct workplace environments. Future studies may explain the slight inconsistencies between samples we observed.

The results of this study suggest that senior leaders, with appropriate encouragement from regulators, should revisit workplace climate initiatives. A multi-climate approach is needed to grapple with the hitherto intractable issue of UPB. Four key messages from this study are the need to promote concern for external stakeholders such as customers, rather than self-interest; ensure that risk issues and policy breaches are never tolerated, ignored or downplayed; inculcate proactive behavioural norms for identifying, reporting, analysing, discussing and escalating issues of concern; and ensure that managers throughout the organisation are effective role models and advocates for risk management. The findings have implications for performance measurement and reward mechanisms, for employee/manager training programs, for resourcing of the risk function and for organisational communications including statements of organisational values.

Despite the strength of using three independent heterogeneous samples, our findings are limited by the crosssectional nature of employee surveys which limits the interpretation of causality. Future researchers could consider supplementing self-report perception data with actual reporting of unethical behaviours where these are systematically recorded. Given our focus has been on ESI climate, future studies could focus on other ethical climates to continue this nuanced understanding of UPB antecedents. Investigation in other regulatory environments and in organisations with more favourable risk climate may also enhance our understanding.

Through investigation of ESI and risk climates in three separate samples, we found that a multi-climate approach is likely to be most effective for addressing the undesirable unethical, pro-organisational employee behaviour that has drawn so much world-wide attention. Workplace climates that are low in self-interest and that encourage employees to consider external stakeholders should be the first priority for reducing UPB. We demonstrate that the combination of favourable risk climate-namely low avoidance, high proactive and high manager-with low ESI climate, results in optimum workplace conditions for reducing potential UPB. Practitioners and researchers should be aware that both risk and ethical climates matter to reduce UPB.

Acknowledgements This research has been conducted with financial sponsorship from EMC Corporation, the parent company of RSA Security LLC, a provider of systems for governance, risk and compliance i.e. RSA Archer® Suite of products. We gratefully acknowledge advisory support from the following organisations: Australian Securities and Investment Commission, Financial Services Council, Mercer Australia and RSA Archer. Survey administration/reporting was conducted with the assistance of Voice Project. Research assistant Lina Tong provided statistical analysis of survey data. The three organisations that allowed us survey access have also played a vital role. While they must remain nameless, their generous contribution for the good of the industry is deeply appreciated. No individual or organisation had any right of review with regard to this publication, except (where relevant) to ensure that they could not be identified.

\section{Compliance with Ethical Standards}

Conflicts of interest Both Patrick Garcia and Denise Jepsen attest that they have no potential conflicts of interest. Elizabeth Sheedy has disclosed that she has, in the past, received research funding and in-kind support from the following organisations (in addition to those men- 
tioned in the Acknowledgements): Centre for International Finance Research, Australian Prudential Regulation Authority, Deloitte Australia, Insurance Council of Australia, Australia and New Zealand Institute for Insurance and Finance, Financial Services Institute of Australia and 17 individual financial institutions. She has consulted to the Royal Commission into Misconduct in the Banking, Superannuation and Financial Services Industry. Under a commercialisation agreement with the university, she may potentially receive royalties from the commercial use of the Macquarie University Risk Climate Scale.

Ethical approval All procedures performed in studies involving human participants were in accordance with the ethical standards of Macquarie University (approvals 5201300285 and 5201830633436) and the National Statement of Ethical Conduct in Human Research, updated 2018, produced by the Australian Research Council.

Open Access This article is licensed under a Creative Commons Attribution 4.0 International License, which permits use, sharing, adaptation, distribution and reproduction in any medium or format, as long as you give appropriate credit to the original author(s) and the source, provide a link to the Creative Commons licence, and indicate if changes were made. The images or other third party material in this article are included in the article's Creative Commons licence, unless indicated otherwise in a credit line to the material. If material is not included in the article's Creative Commons licence and your intended use is not permitted by statutory regulation or exceeds the permitted use, you will need to obtain permission directly from the copyright holder. To view a copy of this licence, visit http://creativecommons.org/licenses/by/4.0/.

\section{References}

Aiken, L. S., West, S. G., \& Reno, R. R. (1991). Multiple regression: Testing and interpreting interactions. Thousand Oaks, CA: Sage.

Arnaud, A., \& Schminke, M. (2012). The ethical climate and context of organizations: A comprehensive model. Organization Science, 23(6), 1767-1780.

APRA. (2013). Prudential Practice Guide SPG 220 Risk Management. Retrieved from https://www.apra.gov.au/Super/PrudentialFrame work/Documents/Prudential-Practice-Guide-SPG-220-RiskManagement-July-2013.pdf

ASFA. (2017). The Australian Superannuation Industry March 2017 file:///D:/Users-Data/mq93500475/Downloads/1703_The_Australian_superannuation_industry\%20(2).PDF.

Bennett, R. J. (1998). Perceived powerlessness as a cause of employee deviance. In R. Griffin, A. O'Leary Kelley, \& J. Collins (Eds.), Dysfunctional workplace behavior (pp. 221-239). Greenwich, CT: JAI Press.

Bennett, R. J., \& Robinson, S. L. (2000). Development of a measure of workplace deviance. Journal of Applied Psychology, 85(3), 349.

Castille, C. M., Buckner, J. E., \& Thoroughgood, C. N. (2018). Prosocial citizens without a moral compass? Examining the relationship between Machiavellianism and unethical pro-organizational behavior. Journal of Business Ethics, 149(4), 919-930.

Chen, M., Chen, C. C., \& Sheldon, O. J. (2016). Relaxing moral reasoning to win: How organizational identification relates to unethical pro-organizational behavior. Journal of Applied Psychology, 101(8), 1082.

Chung, J., \& Monroe, G. S. (2003). Exploring social desirability bias. Journal of Business Ethics, 44(4), 291-302.

Dov, Z. (2008). Safety climate and beyond: A multi-level multi-climate framework. Safety Science, 46(3), 376-387.
Ehrhart, M. G., Schneider, B., \& Macey, W. H. (2013). Organizational climate and culture: An introduction to theory, research, and practice. London: Routledge.

Effelsberg, D., Solga, M., \& Gurt, J. (2014). Transformational leadership and follower's unethical behavior for the benefit of the company: A two-study investigation. Journal of Business Ethics, 120(1), 81-93.

Financial Stability Board. (2013). Thematic Review on Risk Governance. Retrieved from https://www.fsb.org/wp-content/uploa ds/r_130212.pdf

Financial Stability Board. (2014). Guidance on Supervisory Interaction with Financial Institutions on Risk Culture; A Framework for Assessing Risk Culture. Retrieved from.https://www.fsb.org/ wp-content/uploads/140407.pdf.

Fuller, C. M., Simmering, M. J., Atinc, G., Atinc, Y., \& Babin, B. J. (2016). Common methods variance detection in business research. Journal of Business Research, 69(8), 3192-3198.

Garcia, P. R. J. M., Wang, L., Lu, V., Kiazad, K., \& Restubog, S. L. D. (2015). When victims become culprits: The role of subordinates' neuroticism in the relationship between abusive supervision and workplace deviance. Personality and Individual Differences, 72, 225-229.

Guardian. (2016). PPI Claims-All you need to know about the misselling scandal. Retrieved from https://www.theguardian.com/ business/2016/aug/02/ppi-claims-all-you-need-to-know-about -the-mis-selling-scandal

Hart, C. M., Ritchie, T. D., Hepper, E. G., \& Gebauer, J. E. (2015). The balanced inventory of desirable responding short form (BIDR-16). Sage Open, 5(4), 1-9.

Institute of International Finance (IIF). (2008). Final Report of the IIF Committee on Market Best Practices: Principles of Conduct and Best Practice Recommendations.

International Organisation for Standardization. (2018). ISO 31000. 2009. Risk management Retrieved from https://www.iso.org/ iso-31000-risk-management.html

Jiang, K., Hu, J., Hong, Y., Liao, H., \& Liu, S. (2016). Do it well and do it right: The impact of service climate and ethical climate on business performance and the boundary conditions. Journal of Applied Psychology, 101(11), 1553.

Keller, S., \& Aiken, C. (2009). The inconvenient truth about change management. Retrieved from https://www.aascu.org/corporatep artnership/McKinseyReport2.pdf

Kish-Gephart, J. J., Harrison, D. A., \& Treviño, L. K. (2010). Bad apples, bad cases, and bad barrels: Meta-analytic evidence about sources of unethical decisions at work. Journal of Applied Psychology, 95(1), 1.

Kohlberg, L. (1984). The Psychology of moral development. San Francisco: Harper and Rowe.

Kuenzi, M., \& Schminke, M. (2009). Assembling fragments into a lens: A review, critique, and proposed research agenda for the organizational work climate literature. Journal of Management, 35(3), 634-717.

Lawrence, T. B., \& Robinson, S. L. (2007). Ain't misbehavin: Workplace deviance as organizational resistance. Journal of Management, 33(3), 378-394.

Lee, A., Schwarz, G., Newman, A., \& Legood, A. (2017). Investigating when and why psychological entitlement predicts unethical pro-organizational behavior. Journal of Business Ethics, 154(1), $109-126$.

Marin, M. (2012). The Crisis of Shareholder Primacy. Retrieved from https://www.cam.ac.uk/research/discussion/the-crisis-ofshareholder-primacy.

Martin, K. D., \& Cullen, J. B. (2006). Continuities and extensions of ethical climate theory: A meta-analytic review. Journal of Business Ethics, 69(2), 175-194. 
Matherne, C. F., III, \& Litchfield, S. R. (2012). Investigating the relationship between affective commitment and unethical proorganizational behaviors: The role of moral identity. Journal of Leadership, Accountability and Ethics, 9(5), 35-46.

Miao, Q., Newman, A., Yu, J., \& Xu, L. (2013). The relationship between ethical leadership and unethical pro-organizational behavior: Linear or curvilinear effects? Journal of Business Ethics, 116(3), 641-653.

Mikes, A. (2009). Risk management and calculative cultures. Management Accounting Research, 20(1), 18-40.

Morrison, E. W. (2006). Doing the job well: An investigation of pro-social rule breaking. Journal of Management, 32(1), 5-28.

Myer, A. T., Thoroughgood, C. N., \& Mohammed, S. (2016). Complementary or competing climates? Examining the interactive effect of service and ethical climates on company-level financial performance. Journal of Applied Psychology, 101(8), 1178.

Nocco, B. W., \& Stulz, R. M. (2006). Enterprise risk management: Theory and practice. Journal of Applied Corporate Finance, 18(4), 8-20.

Ostroff, C., Kinicki, A. J., \& Muhammad, R. S. (2012). Organizational culture and climate. In N. W. Schmitt \& S. Highhouse (Eds.), Handbook of psychology (2nd ed.). New York: Wiley.12

OECD. (2014). Risk Management and Corporate Governance, Corporate Governance, OECD Publishing. https://doi. org/10.1787/9789264208636-en

Palermo, T., Power, M., \& Ashby, S. (2017). Navigating institutional complexity: The production of risk culture in the financial sector. Journal of Management Studies, 54(2), 154-181.

Peterson, D. K. (2002). The relationship between unethical behavior and the dimensions of the ethical climate questionnaire. Journal of Business Ethics, 41(4), 313-326.

Podsakoff, P. M., MacKenzie, S. B., Lee, J. Y., \& Podsakoff, N. P. (2003). Common method biases in behavioral research: A critical review of the literature and recommended remedies. Journal of Applied Psychology, 88(5), 879.

Power, M. (2004). The risk management of everything. The Journal of Risk Finance, 5(3), 58-65.

Royal Commission into Misconduct in the Banking, Insurance, Superannuation and Financial Services Industry. (2018). Interim Report Volume 1. Retrieved from https://financialservices.royalcommi ssion.gov.au/Documents/interim-report/interim-report-volume-1. pdf.

Royal Commission into Misconduct in the Banking, Insurance, Superannuation and Financial Services Industry. (2019). Final Report Volume 1. Retrieved from https://financialservices.royalcommi ssion.gov.au/Pages/reports.aspx\#final

Schneider, B., Ehrhart, M. G., \& Macey, W. H. (2013). Organizational climate and culture. Annual Review of Psychology, 64, 361-388.

Schminke, M., Ambrose, M. L., \& Neubaum, D. O. (2005). The effect of leader moral development on ethical climate and employee attitudes. Organizational behavior and human decision processes, 97(2), 135-151.
Senior Supervisor's Group. (2009). Risk Management Lessons from the Global Crisis of 2008. Retrieved from https://www.sec.gov/ news/press/2009/report102109.pdf

Sheedy, E. A., Griffin, B., \& Barbour, J. P. (2017). A framework and measure for examining risk climate in financial institutions. Journal of Business and Psychology, 32(1), 101-116.

Sheedy, E. A., \& Griffin, B. (2018). Risk governance, structures, culture, and behavior: A view from the inside. Corporate Governance: An International Review.

Sheedy, E., Zhang, L., \& Tam, K. C. H. (2019). Incentives and culture in risk compliance. Journal of Banking \& Finance, 107, 105611.

Simha, A., \& Cullen, J. B. (2012). Ethical climates and their effects on organizational outcomes: Implications from the past and prophecies for the future. The Academy of Management Perspectives, 26(4), 20-34.

Stewart, R., Volpone, S. D., Avery, D. R., \& McKay, P. (2011). You support diversity, but are you ethical? Examining the interactive effects of diversity and ethical climate perceptions on turnover intentions. Journal of Business Ethics, 100(4), 581-593.

Tayan, B. (2016). The Wells Fargo Cross-Selling Scandal. Rock Center for Corporate Governance at Stanford University Closer Look Series: Topics, Issues and Controversies in Corporate Governance No. CGRP-62; Stanford University Graduate School of Business Research Paper No. 17-1. Retrieved from SSRN: https://ssrn.com/ abstract $=2879102$.

Treviño, L. K., den Nieuwenboer, N. A., \& Kish-Gephart, J. J. (2014). (Un) ethical behavior in organizations. Annual Review of Psychology, 65, 635-660.

Victor, B., \& Cullen, J. B. (1987). A theory and measure of ethical climate in organizations. Research in Corporate Social Performance and Policy, 9(1), 51-71.

Victor, B., \& Cullen, J. B. (1988). The organizational bases of ethical work climates. Administrative Science Quarterly, 33, 101-125.

Umphress, E. E., Bingham, J. B., \& Mitchell, M. S. (2010). Unethical behavior in the name of the company: The moderating effect of organizational identification and positive reciprocity beliefs on unethical pro-organizational behavior. Journal of Applied Psychology, 95, 769-780.

Umphress, E. E., \& Bingham, J. B. (2011). When employees do bad things for good reasons: Examining unethical pro-organizational behaviors. Organization Science, 22(3), 621-640.

Wimbush, J. C., Shepard, J. M., \& Markham, S. E. (1997). An empirical examination of the relationship between ethical climate and ethical behavior from multiple levels of analysis. Journal of Business Ethics, 16(16), 1705-1716.

Publisher's Note Springer Nature remains neutral with regard to jurisdictional claims in published maps and institutional affiliations. 